Revista lus et Praxis, Año 24, No 3, 2018, pp. 133 - 172

ISSN 0717 - 2877

Universidad de Talca - Facultad de Ciencias Jurídicas y Sociales

Sobreendeudamiento y exoneración legal de los saldos insolutos en el procedimiento concursal del consumidor

Guillermo Caballero Germain

Trabajo recibido el 6 de septiembre de 2017 y aprobado el 30 de mayo de 2018

\title{
Sobreendeudamiento y exoneración legal de los saldos insolutos en el procedimiento concursal del consumidor
}

\section{OVERINDEBTEDNESS AND DISCHARGE IN THE CONSUMER BANKRUPTCY}

\author{
Guillermo Caballero Germain* \\ "Los dones que provienen de la justicia son superiores a los que se originan en la caridad"
}

Gibran Khalil "El profeta"

RESUMEN

El trabajo plantea un análisis crítico de la regla de exoneración legal de los saldos insolutos en el procedimiento concursal de una persona deudora. La configuración actual de la regla es excesivamente generosa y las reacciones "correctivas" de autoridades, tanto judiciales como administrativas, tampoco han logrado una solución razonable. En ese escenario, las bases para una reconstrucción del discharge son la comprensión, por una parte, del sobreendeudamiento como un problema social y, por otra parte, de la exoneración legal de los saldos insolutos como una regla redistributiva cuya finalidad es la tutela preferente del consumidor de buena fe, como lo muestra el derecho comparado. Así entendido, el discharge no sólo modifica la función del procedimiento concursal, sino también afecta el sistema de derecho de las obligaciones.

\section{ABSTRACT}

This paper analyses critically the discharge rule in the consumer bankruptcy procedure. The current text is overly generous and the "remedial" actions taken by judicial and administrative authorities have been unsatisfactory. Within this context, the basis for rebuild the discharge rule are the understanding, on the one hand, of overindebtedness as a social problem and, on the other hand, the discharge as a redistributive rule that its ultimate goal is to protect the honest consumer, as shown by the comparative law analysis. Seen in this light, the discharge not only modifies the function of the insolvency procedure, but also alters the law of obligation system.

Palabras Clave

Exoneración legal, sobreendeudamiento, consumidor

KEY WORDS

Discharge, overindebtedness, consumer

\section{Introducción}

En junio de este año, un consumidor solicitó el inicio de un procedimiento concursal de liquidación en razón de tener deudas por la suma total de

\footnotetext{
* Profesor asistente de Derecho Comercial de la Universidad de Chile. Doctor en Derecho por la Universidad Autónoma de Madrid. Correo electrónico: gcaballero@derecho.uchile.cl.
} 
\$13.154.794.- pesos, indicando como únicos bienes afectos al concurso: un televisor plasma Samsumg 32"; un taladro Bauker y una sierra caladora Skil, siendo su remuneración mensual la suma de \$550.000.- pesos ${ }^{1}$. Es improbable que una persona en las referidas circunstancias sea capaz de cumplir las obligaciones crediticias mencionadas. En ese caso, una buena pregunta es si el ordenamiento jurídico debe prestar una particular tutela a un sujeto en la coyuntura descrita o se trata de una situación de la cual debe, de acuerdo al derecho común, responder el deudor, con sus bienes presentes y futuros (ex artículo 2465 Cc.).

La Ley N $N^{\circ} 20.720$ sobre reorganización y liquidación de empresas y personas $\left(\mathrm{NLC}^{2}\right)$ responde la pregunta antes formulada rechazando la solución tradicional contenida en nuestro código civil (garantía general patrimonial) y otorgando una fuerte tutela jurídica al consumidor insolvente 3 . Esa especial protección consiste en la exoneración legal de los saldos insolutos de las deudas anteriores al inicio de un procedimiento concursal de una persona deudora (discharge), a fin de crear las condiciones para el reinicio de una actividad productiva ("segunda oportunidad" o fresh start) ${ }^{4}$.

En este trabajo nos interesa analizar críticamente la figura del discharge, cuya defectuosa construcción legal genera importantes problemas, no sólo de aplicación por parte de nuestros tribunales, sino de la comprensión del concurso del consumidor como una institución pro debitoris. Una correcta comprensión de la referida regla de exoneración legal de los saldos insolutos exige una mirada a las causas, económicas y sociales, del sobreendeudamiento de un consumidor y de los efectos de esa regla en el mercado crediticio. Entendidas esas cuestiones será posible reconocer cuál es el interés jurídico preferentemente tutelado en el discharge, cómo opera esa protección y cuáles son sus límites.

\footnotetext{
1 9 Juzgado Civil de Santiago, rol No C-9485-2017.

${ }^{2}$ Ley No 20.720, publicada en el Diario Oficial de 9 de enero de 2014.

${ }^{3}$ Sobre los efectos sustantivos del concurso, remito al lector interesado a GarRIDO (1999), p. 10, con ulteriores referencias bibliográficas; CNUDMI (2006), p. 23.

${ }^{4}$ La noción de "persona deudora" en la NLC no coincide enteramente con la de consumidor. La fractura surge de la inclusión de consumidores dentro de la noción de empresa deudora. No obstante esta problemática construcción del ámbito de aplicación subjetivo de los distintos procedimientos concursales contenidos en la NLC, a los efectos de este trabajo, entenderemos los términos consumidor y persona deudora como sinónimos pues, queda en pie que toda persona deudora es un consumidor. Al hilo de lo anterior, cabe precisar que el presente estudio se circunscribe al estudio de la exoneración legal de los saldos insolutos en el marco de la insolvencia de una persona deudora (cuya regulación es una novedad muy meritoria), no obstante que la NLC establece el beneficio de la exoneración legal de los saldos insolutos en el procedimiento concursal de liquidación de una empresa deudora, apartándose no sólo de nuestra propia tradición jurídica, sino también de la tendencia actual del Derecho comparado. De esto último esperamos ocuparnos en un próximo trabajo.
} 
La exposición toma como punto de partida la descripción del fenómeno del sobreendeudamiento (1) y sigue con el análisis de los rasgos contemporáneos del discharge como respuesta jurídica al problema del excesivo endeudamiento, para lo cual se ha tenido a la vista otros ordenamientos (2). Las siguientes secciones abordan la regulación de la exoneración legal de los saldos insolutos en la NLC, cuya relevancia en nuestro ordenamiento se ha visto opacada por su problemática formulación legal (3), lo cual ha provocado una inusitada reacción de las autoridades administrativas y judiciales (4). El apartado final elabora una propuesta de criterios de solución de lege lata y de lege ferenda (5).

\section{El sobreendeudamiento como patología del consumo}

\subsection{La democratización del crédito}

El acceso al crédito para grupos de personas tradicionalmente excluidos del sistema financiero es un fenómeno relativamente reciente a nivel mundial. El explosivo aumento del número de tarjetas de créditos en las últimas décadas muestra de buena forma ese mayor acceso al crédito. Así, por ejemplo, en Estados Unidos de América (USA), entre los años 1989 a 2001, en el quintil más bajo, las tarjetas de crédito aumentaron un $46,5 \%{ }^{5}$. En nuestro país, para el período 1993-2007, las tarjetas de crédito no bancarias aumentaron desde 1.350 .000 a 19.273.9196. Esta ampliación del mercado crediticio -la denominada "democratización del crédito" - es un antecedente imprescindible para la comprensión del endeudamiento como un fenómeno social y está directamente vinculada a una política pública de favorecimiento del acceso al crédito apoyada en la evidencia ofrecida por los economistas.

La literatura económica ha demostrado empíricamente una relación positiva entre el crecimiento económico y el desarrollo del sistema financiero. El crédito permite a una persona satisfacer sus necesidades actuales con cargo a futuros ingresos. Así, por ejemplo, puede mitigar variaciones transitorias de sus ingresos o anticipar la adquisición de bienes y servicios, incluso de alto valor y, por esa vía, aumentar su bienestar personal y participar en la actividad económica como consumidor. Asimismo, la literatura económica sugiere que el acceso al crédito constituye una importante herramienta para combatir la pobreza y la desigualdad de los ingresos: el desarrollo del sistema financiero-se

\footnotetext{
${ }^{5}$ JOHNSON (2005), p. 475.

${ }^{6}$ Montero y Tarziján (2010), pp. 3 y 5. Las tarjetas de crédito no bancarias rondaron los 25 millones en los años 2007-2008, disminuyendo abruptamente hasta los 7 millones el año 2015 debido a nuevas regulaciones crediticias, como la reducción de la tasa máxima convencional y la eliminación parcial de la información comercial de los deudores (CCS (2016), p. 28).
} 
indica- impacta positivamente en los quintiles más pobres y puede explicar hasta el $60 \%$ del aumento de los ingresos en ese sector, así como una disminución del coeficiente Gini ${ }^{7}$.

En Chile, estudios muestran también esa correlación positiva entre el desarrollo del sistema financiero y el crecimiento económico. Se sostiene que el aumento del ingreso per capita entre los años 1986 al 2001 se debe, en parte significativa, al crecimiento del sistema financiero, donde la reforma al sistema de pensiones ocupa un lugar central ${ }^{8}$. El acceso al crédito por parte de los quintiles más bajos se debe al exitoso desarrollo de las tarjetas de crédito, principalmente aquellas emitidas por casas comerciales ${ }^{9}$. Asimismo, estudios disponibles prueban una correlación positiva entre el desarrollo del sistema financiero y la disminución de la pobreza en nuestro país entre los años 1987 y $2000^{10}$.

De las cifras indicadas se colige que, durante las últimas décadas, los consumidores, especialmente de los quintiles más bajos, han tenido un mayor acceso al crédito y con ello han aumentado su bienestar, a cambio, sin embargo, de un mayor endeudamiento, según se explicará seguidamente.

\subsection{El lado oscuro del mayor acceso al crédito: el sobreendeudamiento}

Un efecto no deseado del mayor acceso al crédito por parte de los consumidores es el sobreendeudamiento. De acuerdo a un estudio del Fondo Monetario Internacional, para el período 2002-2005, el crecimiento promedio real anual del crédito de los hogares alcanzó, a nivel mundial, un $21 \%$, en contraste con un aumento del PIB de un 4,1\%. La mediana de la ratio deuda hogares sobre PIB en los países emergentes aumentó de un 15\% en el año 2008 a un $21 \%$ en el año $2016^{11}$. En Chile, para el período 2000-2009, la tasa de crecimiento promedio de la deuda total de los hogares fue de un $12,8 \%$ anual; muy superior al 3,6\% del promedio de crecimiento de la economía ${ }^{12}$. Esa tendencia

\footnotetext{
${ }^{7}$ BeCK y otros (2007), pp. 14 y 20.

${ }^{8}$ Hernández y Parro (2005), p. 114; Corbo y Schmidt-Hebbel (2003), p. 316.

${ }^{9}$ Montero y Tarziján (2010), p. 5.

${ }^{10}$ BeCK y otros (2007), p. 22.

${ }^{11}$ FMI (2012A), p. 54.

12 BCCH (2010), p. 65. El incremento en el número de personas deudoras en los últimos años en Chile es fácilmente comprobable: a septiembre de 2011, existían 9,5 millones de deudores, en comparación a 11,2 millones de deudores, a diciembre de 2016 (EQUIFAX-USS (2017), p. 4).
} 
continúa: el porcentaje de hogares con deuda aumenta de un 69,6\% (2007) a un $72,6 \%(2017)^{13}$.

Una persona deja de beneficiarse de las ventajas del crédito cuando la carga financiera se torna insoportable, fenómeno usualmente denominado como sobreendeudamiento. Según el grado de control por parte del deudor, las causas de excesivo endeudamiento suelen dividirse en activas (exceso de créditos, mala administración, gastos domésticos y exceso de cobros) y pasivas (pérdida del empleo, divorcio, enfermedad o accidente, disminución del ingreso, muerte, entre otras $)^{14}$. Si bien la literatura económica enseña que el sobreendeudamiento surge usualmente de una combinación de factores, el desempleo y la enfermedad presentan una gran incidencia ${ }^{15}$. De lo anterior se desprende que, mayoritariamente, el sobreendeudamiento es pasivo. De esta forma, de acuerdo a los datos disponibles el sobreendeudamiento aparece como un problema cuyo origen generalmente escapa de la esfera de control del deudor y, como veremos seguidamente, sus efectos también superan esa esfera individual.

En la literatura económica, no existe consenso acerca de cuáles deben ser los criterios para determinar qué es el sobreendeudamiento ${ }^{16}$. Por esa razón,

\footnotetext{
${ }_{13}^{13}$ BcCH (2014), p. 18. Para el período 2001-2015, la ratio deuda sobre ingreso de los hogares chilenos subió de 35 a 63 (BCCH (2015), p. 6 y BCCH (2016), p. 8.

${ }^{14}$ Ramsay (2017), p. 20; Rodríguez Espitia (2013), p. 370; Kemelmajer (2008), p. 16. En Chile, Ruz Lártiga califica el sobreendeudamiento como un fenómeno pluridisciplinar y multicausal, analizándolo desde distintas perspectivas: sociológica, psico-económica, clínico-médica y jurídica (Ruz LárTIGA (2017), pp. 485-508. La distinción entre sobreendeudamiento pasivo y activo ha sido considerada en el ordenamiento español: "muchas situaciones de insolvencia son debidas a factores que escapan del control del deudor de buena fe, planteándose entonces el fundamento ético de que el ordenamiento jurídico no ofrezca salidas razonables a este tipo de deudores que, por una alteración totalmente sobrevenida e imprevista de sus circunstancias, no pueden cumplir los compromisos contraídos" (Exposición de motivos, Real Decreto Ley № 1 de 2015, de 27 de febrero, de mecanismo de segunda oportunidad, reducción de carga financiera y otras medidas de orden social). En cuanto al sobreendeudamiento activo, la jurisprudencia francesa ha declarado estar de mala fe un deudor si contrajo numerosas nuevas deudas sabiendo que no podrá pagarlas o adquirió bienes que no eran de estricta necesidad, agravando su condición de endeudamiento (Kemelmajer (2008), p. 30). Más antecedentes sobre el régimen francés en Ruz LÁrtiga (2017), pp. 508-512.

${ }^{15}$ Kilborn (2008), p. 590; Ramsay (2017), p. 19. En Chile, Ruiz Tagle y otros (2013), pp. 37 y 49-50.

${ }^{16}$ FondevilLe y otros (2010), pp. 3-6; BIS, (2011), p. 40. La Comisión Europea ha propuesto los criterios siguientes: "Comparably high commitments payments that pushes the household below the poverty threshold; Structural arrears on at least one financial commitment; Burden of monthly commitment payments (housing costs inclusive of mortgage payment or rent and payment for other loans) considered to be a heavy burden by the household; Payment capacity considered to be 'very difficult' or 'difficult' by the household; and Illiquidity (an inability to meet an unexpected expense)" (European Comission (2008), sec. 3.4.2.). Un reciente estudio sostiene que los criterios frecuentemente utilizados para medir el sobreendeudamiento pueden dividirse en cuatro categorías: i) según el costo del pago de la deudas, existe sobreendeudamiento si los hogares: a) destinan más del 30\% (o el 50\%) de los ingresos brutos
} 
las cifras de sobreendeudamiento suelen presentar resultados discrepantes. Esta realidad es fácilmente comprobable en Chile.

Un estudio para nuestro país consideró que existe sobreendeudamiento en un hogar si su ratio deuda sobre ingreso es mayor a 0,5 o si su ratio de carga financiera sobre ingreso es mayor a 0,8. Conforme a esos criterios, el estudio arrojó como resultado que entre un 5\% y un 30\% de los hogares chilenos podrían estar sobreendeudados (aunque una vez depurados esos datos, especialmente respecto a la medición de ingresos, el nivel de sobreendeudamiento baja ${ }^{17}$. Todo lo anterior, sostiene este estudio, Ileva a la conclusión de que, no obstante el endeudamiento ha aumentado durante las últimas décadas, esa proporción es mayor en los hogares de menores ingresos. El mayor endeudamiento de ese grupo de hogares no genera un riesgo sistémico, pero puede afectar ciertas entidades financieras altamente concentradas en esos segmentos de mercado ${ }^{18}$.

Como indicamos, los resultados de los estudios disponibles no son coincidentes. Otro estudio más reciente, considerando un hogar vulnerable como aquel que destina un $30 \%$ o más de su ingreso mensual a pagar una deuda no hipotecaria, arroja como resultado que un 30\% (702.765 hogares con deuda no hipotecaria) muestra sobreendeudamiento, con una alta concentración (49\%) en los hogares pertenecientes a los deciles 1 a $5^{19}$.

Un último estudio, aún más reciente, sobre morosidad analiza el sobreendeudamiento conforme al número de créditos por hogar (sobre 4 créditos impagos): de un total de 4.295 .957 personas naturales en mora en el pago de una obligación crediticia, un 40,1\% presenta un sobreendeudamiento (cinco o más cuotas impagas correspondientes a créditos distintos $)^{20}$.

mensuales al pago de deudas (con o sin garantía); b) destinan más del 25\% de los ingresos brutos mensuales al pago de deudas sin garantía, y c) caen bajo la línea de pobreza debido al pago de deudas; ii) según la mora: existe sobreendeudamiento si los hogares presentan más de dos meses en mora en el pago de créditos o cuentas; iii) según número de préstamos, existe sobreendeudamiento si presentan cuatro o más créditos; iv) según la percepción subjetiva, existe sobreendeudamiento si los hogares declaran el pago de sus créditos como una carga financiera pesada (D'ALESSIO y IEZZI (2013), p. 7).

${ }^{17}$ RUIz TAGLE y otros (2013), pp. 9-10 y 36-37. Este estudio se elabora en base a los datos contenidos en la Encuesta de Protección Social (EPS) 2004, 2006 y 2009 y a la Encuesta Financiera de Hogares 2007, 2008 y 2009, utilizando un conjunto de factores objetivos para medir el sobreendeudamiento (ratio deuda sobre ingreso $(\mathrm{RDI})$, ratio de carga financiera sobre ingreso $(\mathrm{RCl})$, margen financiero negativo (MFN), número de créditos (NC), entre otros). Los autores destacan la fuerte incidencia del desempleo en el aumento de los niveles de sobreendeudamiento (p. 37), en lo que coinciden otros estudios sobre la realidad en Europa (KILBORN (2008), p. 590).

${ }^{18}$ Ruiz Tagle y otros (2013), pp. 56-57.

${ }^{19}$ PINTO (2016), p. 5, utilizando los datos de la Encuesta Financiera de Hogares 2014.

${ }^{20}$ EQUIFAX - USS (2017), p. 40. La existencia de cuentas impagas es también un criterio objetivo utilizado en Reino Unido (BIS (2011), p. 40). 
De todos los estudios revisados y a pesar de la disparidad de resultados, se puede observar una concordancia en dos hechos: la existencia de un sobreendeudamiento creciente en Chile y que éste afecta con más fuerza a los hogares con menores ingresos.

\subsection{El excesivo endeudamiento del consumidor como problema social}

A nivel internacional, existe consenso en que el sobreendeudamiento es un problema que excede el ámbito de las finanzas individuales. La impotencia de un deudor para cumplir con sus obligaciones crediticias repercute negativamente en su salud física y mental (ansiedad, stress, depresión, hipertensión, entre otras manifestaciones $)^{21}$. Fuera del ámbito individual, el sobreendeudamiento afecta negativamente al entorno directo del deudor (cónyuge e hijos, especialmente), no sólo por la imposibilidad de desarrollar una vida normal a consecuencia de la falta de medios materiales, sino por la propia aflicción al contemplar las dificultades personales del deudor ${ }^{22}$.

En Chile, un reciente estudio muestra una positiva correlación entre sobreendeudamiento y síntomas de depresión con mayor incidencia en los hogares con deuda de consumo pertenecientes a los quintiles más bajos ${ }^{23}$.

Desde una perspectiva macroeconómica, el sobreendeudamiento puede constituir un riesgo sistémico para el sistema financiero. En la medida que las entidades concedentes de crédito desconocen la débil situación patrimonial del deudor o conociéndola, no reflejan la menor calidad de los respectivos créditos, la información disponible en el mercado acerca de la calidad crediticia de esas instituciones será incompleta. La reciente crisis financiera mundial del año 20072009 (USA) y 2010-2012 (EU), coloquialmente conocida como "crisis subprime", es un ejemplo de las graves consecuencias que conlleva la sobrevaloración de la situación patrimonial de los deudores no sólo para el mercado financiero, sino también para la economía real ${ }^{24}$. El sobreendeudamiento al transformarse en un potencial riesgo sistémico del mercado financiero, deja de ser entendido como un problema privado y pasa a ser una cuestión de política pública, que,

\footnotetext{
${ }^{21}$ Sweet y otros (2013), p. 98; Gathergood (2012), p. 1095; Kemelmajer (2008), p. 18.

${ }^{22} \mathrm{CHOl}(2009)$, pp. 121-122.

${ }^{23}$ Hojman y otros (2016), pp. 59 y 61, sobre la base de los datos contenidos en la Encuesta de Protección Social 2000, 2004, 2006 y 2009 correspondientes a 10.900 hogares.

${ }^{24} W_{\text {в }}(2014), \S 77$ y $\S 81$.
} 
en lo que a este trabajo interesa, cuenta entre sus herramientas la exoneración legal de deudas una vez finalizado el concurso de un consumidor ${ }^{25}$.

\section{El discharge como respuesta normativa al sobreendeudamiento del consumidor}

La causa directa de la incorporación de la exoneración legal de deudas, tras el término del concurso de un consumidor, en numerosos ordenamientos se encuentra en la crisis subprime ${ }^{26}$. Según antes se indicó, la referida crisis dejó en evidencia la importancia sistémica del endeudamiento personal y, por consiguiente, la necesidad de establecer políticas públicas destinadas a facilitar el fresh start y, de esa forma, mitigar las consecuencias negativas del sobreendeudamiento ${ }^{27}$. En ese contexto, la exoneración legal de las deudas anteriores al concurso - una figura de antigua raigambre anglosajona (infra 2.2.1)- emergió como un mecanismo de solución (permanente) a favor del consumidor sobreendeudado, siendo no sólo recomendada por importantes organismos internacionales (entre ellos, el Banco Mundial, el Fondo Monetario Internacional, Insol y Cnudmi), sino efectivamente incorporada en numerosos ordenamientos jurídicos ${ }^{28}$. Este fenómeno ha coincidido con la entrada en vigor de la NLC, al menos, temporalmente. Por todo lo anterior, interesa conocer cuál es la fisonomía a nivel comparado de la regla de exoneración legal de los saldos

\footnotetext{
${ }^{25}$ KILBORN (2008), p. 595. El autor destaca que el cambio del mercado laboral europeo, desde empleos estables de largo tiempo a contratos inestables de corto tiempo, sumado al mayor acceso al crédito, dejan en situación de vulnerabilidad permanente a un sector de la población. Esta configuración del mercado laboral, en tanto se mantenga, constituye un problema estructural de la economía (KILBORN (2008), pp. 588-594). La consecuencia más evidente del carácter estructural (y no coyuntural) de sobreendeudamiento es la necesidad de pasar de mecanismos excepcionales y transitorios (como, por ejemplo, las leyes moratorias) a instrumentos permanentes para combatir sus consecuencias negativas (López SANTA MARÍA (2005), p. 287), entre ellas, destacadamente, la exoneración legal de deudas.

${ }^{26}$ W (2014), §4; RAMSAY (2017), p. 6, quien considera la crisis subprime como el segundo hito, precedido de la crisis de 1987. RAMSAY (2017) nos informa (Tabla 1.1) de los países y reformas en el procedimiento concursal del consumidor y "Debt Adjustment": Bélgica (2009); Chipre (2015), República Checa (2008); Dinamarca (2010); Inglaterra y Gales (2007 y 2015); Estonia (2010); Finlandia (2015); Francia (2010 y 2014); Alemania (2013); Grecia (2010; 2013 y 2015); Hungría (2015); Irlanda (2015); Italia (2012); Latvia (2009; 2010 y 2013); Lituania (2013), Luxemburgo (2013); Holanda (2008), Polonia (2009 y 2014); Portugal (2012); Rumania (2015); Rusia (2015); Eslovaquia (2011); Eslovenia (2015); España (2015) y Suecia (2011).
}

${ }^{27}$ Claessens y otros (2010), p. 275. La protección del consumidor frente al sobreendeudamiento se manifiesta también en la inembargabilidad de ciertos bienes (bienes no afectos al concurso) y fuera del concurso, por ejemplo, en las reglas contrarias a la usura.

${ }^{28}$ W в (2014), §360; FMI (2012B), pp. 91-124; InsOL (2001), pp. 22-24; CNUdmI (2006), pp. 332-335; Liu y Rosenberg (2013), p. 14; Ruz LÁrtiga (2017), p. 1276. 
insolutos (2.1) y la importancia sistémica de su incorporación como institución del concurso (2.2), a lo cual dedicaremos las secciones siguientes.

\subsection{Algunos rasgos comunes del discharge a nivel comparado}

No obstante la creciente incorporación de una regla de exoneración legal de los saldos insolutos en los ordenamientos de diferentes países y el similar propósito perseguido -la liberación del deudor de las deudas previas al concurso $^{29}$-, la configuración precisa de la figura varía en cada sistema jurídico ${ }^{30}$. Precisamente por lo anterior y a fin de contar con un parámetro para contrastar nuestra regulación (infra 3), es útil describir cuáles son los elementos del supuesto de hecho normativo, adicionales al sobreendeudamiento, usualmente presentes a nivel comparado en la regla en estudio, a saber ${ }^{31}$ :

\section{i) La honestidad del deudor}

La exoneración legal de los saldos insolutos tras el término de un procedimiento concursal es una regla de protección del deudor honesto, pero desafortunado ${ }^{32}$. La exigencia de una conducta correcta por parte del deudor en ocasiones se establece apelando a una exigencia genérica de buena $\mathrm{fe}^{33} \mathrm{y}$, en otras, a través de un catálogo de conductas excluyentes del beneficio legal (como, por ejemplo, la omisión u ocultamiento de ciertos bienes o créditos por parte del deudor o la simulación de deudas; el éxito de acciones revocatorias o de simulación; la declaración culpable del concurso o de existencia de responsabilidad penal concursal $)^{34}$. La inexistencia de activo o la presentación de

\footnotetext{
${ }^{29}$ W B (2014), §354.

${ }^{30}$ RAMSAY (2017), p. 6.

${ }^{31}$ No interesa realizar aquí un estudio de derecho comparado de la figura, sino solamente delinear los rasgos más comunes del discharge a nivel internacional. Los lectores interesados en un estudio más profundo del discharge en otros ordenamientos pueden consultar Del Fierro (2012), pp. 75-140; RuZ LÁRTIGA (2017), pp. 1278-1282 o la reciente obra de RAMSAY (2017).

32 Wв (2014), §370; ТАвв (1991), р. 333.

${ }^{33}$ Entre otros países que siguen esta fórmula se cuentan: Francia (arts. L711-1, L724-3 y 742-3 Code de la consommation); USA (11 U.S. Code \$1325(1)); Alemania (\$290 y §296 Insolvenzordnung); España (art. 178 bis(3) Ley concursal, aunque luego lista una serie de requisitos); Colombia (art. 571.1 Ley No 1.564/2012).

${ }^{34}$ Utilizan un catálogo, entre otros, países: Italia (art. 142(1)-(6), Legge Fallimentare y art. 14-terdecies (1)-(2) (del art.18 de la Legge 27 gennaio 2012, Disposizioni in materia di usura e di estorsione, nonché di composizione delle crisi da sovraindebitamento, en adelante, Legge 27 gennaio 2012); Irlanda (sec. 26.2 (e-f) y 27.2 Personal Insolvency Act 2012); Escocia (sec. 137.5(b), Bankruptcy Act 2016); Canadá (sec. 173(1)(c)-(o), Bankruptcy and Insolvency Act), y Uruguay (art. 213 Ley No 18.387/2008).
} 
bienes de escaso valor al momento del inicio del procedimiento concursal no constituyen en sí mismos hechos excluyentes de la buena fe del deudor.

Desde una perspectiva temporal, la concesión del discharge exige una correcta conducta del deudor respecto de la administración de su patrimonio, no sólo antes (al nacimiento de la obligación) y durante el concurso, sino que hasta el total cumplimiento de las obligaciones adquiridas por el consumidor en el procedimiento concursal. Conviene en este punto recordar que las causas más comunes del sobreendeudamiento aparecen vinculadas a hechos, frecuentemente, fuera del control del deudor (como la pérdida del empleo o problemas de salud; supra 1.2). En esos casos, la exigencia de buena fe pretende evitar abusos no en relación al origen del sobreendeudamiento, sino respecto al comportamiento posterior del deudor, según se explicará seguidamente.

\section{ii) El cumplimiento de un plan de pagos}

La obtención del beneficio legal de la exoneración de las deudas suele quedar sujeto a la exigencia de un pago mínimo (por ejemplo, un 10\% de la deuda) o del sometimiento del deudor a un plan de pagos acordado con los acreedores y aprobado por un tribunal u órgano administrativo (por períodos variables, usualmente, 3 años) ${ }^{35}$. Sin embargo, este requisito excluye a los deudores que no están en condiciones de realizar ese pago o de afrontar un plan de pagos. A este respecto es interesante observar que en el caso de los deudores carentes de bienes afectos al concurso (conocidos bajo la sigla NINA: no income, no assets), se puede observar una tendencia a facilitar (no a impedir) el discharge a través de un procedimiento breve y simplificado, sin sujeción a un plan de pagos (de allí denominados "zero plans") ${ }^{36}$.

\footnotetext{
${ }^{35}$ W B (2014), §370; Ramsay (2017), p. 154. Un pago mínimo como requisito para la concesión del discharge se exige en Italia (art. 142, Legge Fallimentare y art. 14-terdecies (1)f Legge 27 gennaio 2012); España (art. 178 bis3.4\%(ii) Ley concursal, aunque puede sustituirse por el cumplimiento de otros requisitos). La duración de los programas de pago varía. Así, en Irlanda se extiende hasta 3 años (sec. 34, Personal Insolvency Act 2012); en USA entre 3 a 5 años (11 U.S. Code §1322(a)(4)). En Alemania el plazo original de 6 años, puede reducirse, a partir del 1 de julio de 2014, hasta los 3 años, si el deudor pagó, al menos, un 35\% de los créditos concursales (\$287.2 y $\$ 300$ Insolvenzordnung, tras la aprobación el año 2013, de la Gesetz zur Verkürzung des Restschuldbefreiungsverfahrens und zur Stärkung der Gläubigerrechte) y en Francia de 7 años (art. L732-3 Code de la consommation). La propuesta de Directiva sobre marcos de reestructuración preventiva, segunda oportunidad y medidas para aumentar la eficacia de los procedimientos de condonación, insolvencia y reestructuración, y por la que se modifica la Directiva 2012/30/UE (Com (2016) 723 final), aplicable sólo a empresarios personas naturales (y extensible a consumidores) establece un plazo máximo de 3 años para obtener el discharge, incluida la duración de un programa de pago (art. 201(b)).

${ }^{36}$ W B (2014), §297-300; RAmsAY (2017), p. 4. Así, por ejemplo, en Francia, si «le débiteur se trouve dans une situation irrémédiablement compromise caractérisée par l'impossibilité manifeste» de cumplir -entre
} 


\section{iii) La concesión fundada del beneficio}

Al hilo de lo anterior, es útil destacar que usualmente la exoneración legal de deudas exige un pronunciamiento específico de la autoridad, judicial o administrativa, sobre el cumplimiento de los requisitos de procedencia del beneficio legal, con independencia de si ese pronunciamiento deba producirse conjuntamente con el cierre del concurso o en una fase posterior. Asimismo, en algunos ordenamientos, los acreedores y el liquidador tiene el derecho a solicitar la revocación del discharge ${ }^{37}$.

En los últimos años, sin embargo, es posible observar la tendencia a conceder un automatic discharge, sin necesidad de una decisión específica del tribunal, sino una vez vencido cierto plazo, cumplidos entre otros requisitos, por ejemplo, la inexistencia de una objeción por parte de un acreedor o del administrador concursal ${ }^{38}$.

\section{iv) La educación financiera del deudor}

La idea de liberar al deudor de las deudas previas al inicio del concurso y generar una "segunda oportunidad" suele exigir también un cambio de hábitos respecto a la forma de manejar el dinero, cuestión a la que puede contribuir

otros- con un plan de pagos, la Commision de surendettement puede «recommander un rétablissement personnel sans liquidation judiciaire si elle constate que le débiteur ne possède que des biens meublants nécessaires à la vie courante et des biens non professionnels indispensables à l'exercice de son activité professionnelle, ou que l'actif n'est constitué que de biens dépourvus de valeur marchande ou dont les frais de vente seraient manifestement disproportionnés au regard de leur valeur vénale» (art. L724-1 Code de la consommation. Sobre la exoneración legal de los saldos insolutos en Francia, LóPEz SAN LuIS (2015), pp. 223-226; Ruz Lártiga (2017), p. 1278). En Reino Unido existe, un procedimiento para deudores con escasos bienes y deudas hasta 20.000 euros (Part 7A Debt relief orders Insolvency Act 1986); 35.000 euros en Irlanda (Debt Relief Notice, DRN). En Nueva Zelandia, en el No Asset Procedure (NAP), sólo se admiten deudas inferiores a 47.000 NZD (sec. 377(1) Insolvency Act 2006).

${ }^{37}$ Así, por ejemplo, en USA (11 U.S. Code $§ 727$ (d) y (e)); Italia (art. 14-terdecies (1)f Legge 27 gennaio 2012).

${ }^{38}$ Los plazos del discharge automático varían en cada legislación. Así, a los 9 meses, contados desde el inicio del procedimiento concursal, en Canadá (sec. 168.1 (1)(a)(i), Bankruptcy and Insolvency Act); a los 12 meses en Reino Unido (sec. 279 Insolvency Act 1986) y Escocia (sec. 137(2), Bankruptcy Act 2016); 3 años en Australia (sec. 149, Bankruptcy Act 1966). En Nueva Zelandia, como regla general, 3 años (sec. 290(1) Insolvency Act 2006) y 12 meses en el NAP (sec. 377(1) Insolvency Act 2006); a los 10 años en Uruguay (art. 213 Ley № 18.387/2008). La situación en USA merece un comentario adicional. Si bien el Chapter 7 aparece como el prototipo del automatic discharge (11 U.S. Code \$727), el acceso al mismo ha sido progresivamente limitado, especialmente, tras la aprobación de Bankruptcy Abuse Prevention and Consumer Protection Act of 2005 (BAPCPA). Bajo la lógica "can pay/should pay", la BACPA establece ciertos criterios ("needs-based bankruptcy relief" o "means test") para impedir a un deudor optar por un automatic discharge si tiene posibilidades de asumir un plan de pagos de acuerdo al Chapter 13 (entre muchos, Ramsay (2017), pp. 57-61). 
una mejor formación en aspectos básicos de economía. Por lo anterior, varios ordenamientos incluyen dentro de los requisitos para la concesión de la exoneración legal de los saldos insolutos la asistencia a cursos de formación básica sobre finanzas ${ }^{39}$.

\section{v) ¿Una tercera oportunidad?}

En concordancia con la idea anterior, en muchos ordenamientos, el discharge es un beneficio al cual es posible acceder una sola vez en la vida o solamente tras un largo plazo desde su obtención, pues se trata de una solución excepcional ${ }^{40}$.

\section{vi) Las deudas exceptuadas}

Si bien el deudor sobreendeudado merece recibir una ayuda extraordinaria a través de la extinción de los saldos insolutos, las consecuencias de ese beneficio no deben afectar a otros sujetos dignos de una tutela legal superior. Por esa razón, en todos los ordenamientos estudiados, la exoneración legal de deudas deja ciertas obligaciones intactas, entre ellas, usualmente: a) los alimentos u otras deudas de familia con hijos y cónyuge ${ }^{41}$; b) las multas y otras sanciones ${ }^{42}$;

\footnotetext{
${ }^{39} W_{\text {B }}$ (2014), §367. La exigencia de recibir el deudor cierta formación financiera se establece, entre otros países, en Escocia (sec. 117, Bankruptcy Act 2016); USA (11 U.S. Code §727(a)(11)); Canadá (sec. 157.1(3) Bankruptcy and Insolvency Act). En Francia, el juez puede sugerir como una medida de ayuda al deudor la realización de un programa de educación financiera (article L742-23 Code de la consommation). Con todo, la literatura económica ha demostrado empíricamente las limitaciones de esta herramienta (ThaleR y SUNSTEIN (2008), pp. 111-122.

${ }^{40}$ WB (2014), §366. Una sola vez en la vida se puede obtener, por ejemplo, en Irlanda bajo un DRF (sec. 57, Personal Insolvency Act 2012) y en Nueva Zelandia, conforme a un NAP (sec. 363(1)(b) Insolvency Act 2006). En otros ordenamientos se exige haber transcurrido 10 años desde la obtención del beneficio: Colombia (art. 571 parr. 2 Ley No 1564/2012); Alemania (\$290.3 Insolvenzordnung); España (Artículo 178 bis $3.5^{\circ}$ (ii) Ley concursal, salvo haya pagado un parte considerable de las deudas concursales). En USA, tras 8 ó 6 años desde la obtención del beneficio en el caso de la liquidación (11 U.S. Code $\$ 727(\mathrm{a})(8)$ y (9)). En Canadá, el automatic discharge se produce en un período retardado de entre 24 y 36 meses después del inicio del procedimiento concursal, si el deudor ha obtenido este beneficio previamente (sec. 168.1 (1)(b), Bankruptcy and Insolvency Act).

${ }^{41} W_{\text {B }}$ (2014), §373-374. Francia (Article L711-4(1)); Irlanda (sec. 2, Excluded debt (a) 26.8(j) Personal Insolvency Act 2012); Reino Unido (sec. 281(5)(b) Insolvency Act 1986); Escocia (Bankruptcy Act 2016, sec. 145.3.f); USA (11 U.S. Code § 523(a)(5) y (15)); Nueva Zelandia (sec. 304(2)(d)-(e) Insolvency Act 2006); Italia (articolo 142(a), Legge Fallimentare y art. 14-terdecies (3)a Legge 27 gennaio 2012); Canadá (sec. 178(1)(b)-(c) Bankruptcy and Insolvency Act).

42 WB (2014), §375-376. Francia (Article L711-4(3) y L711-5); Reino Unido (sec. 10.146 Insolvency Act 2016); Escocia (Bankruptcy Act 2016, sec. 145.3(a)-(e)); Italia (art. 14-terdecies (3)b Legge 27 gennaio 2012); USA (11 U.S. Code § 523(a)(7)).
} 
c) impuestos y otras deudas con la administración ${ }^{43}$; d) préstamos educacionales ${ }^{44}$; e) deudas por responsabilidad penal ${ }^{45}$, y f) deudas por responsabilidad extracontractual $^{46}$.

\section{vi) El efecto extintivo}

En la mayoría de los países, el discharge extingue las obligaciones pendientes de pago tras el cierre del concurso. En otros ordenamientos, el efecto es la inexigibilidad de las referidas deudas ${ }^{47}$. Aparentemente, el punto tiene importancia respecto del destino de las cauciones constituidas por terceros a favor del deudor. En efecto, si en virtud de la exoneración legal se extingue la obligación principal, puede sostenerse, que también debería extinguirse la obligación accesoria. En cambio, si la deuda subsiste, aunque el acreedor carece de acción para exigir su cumplimiento al deudor insolvente (obligación natural), puede entenderse que la garantía no debe extinguirse. Sin embargo, no debe exagerarse la relevancia de una u otra opción sobre la subsistencia de las garantías de terceros, pues los resultados finales suelen ser semejantes. Las garantías exógenas subsisten no sólo en los ordenamientos donde se establece como efecto del discharge la inexigibilidad del pago de los saldos insolutos, sino también, generalmente, allí donde se opta por la extinción debido a que, en este último caso, o bien la ley expresamente afirma la subsistencia de las garantías constituidas por terceros, o bien la jurisprudencia así lo ha declarado ${ }^{48}$.

\footnotetext{
${ }^{43}$ WB (2014), §377-378. USA (11 U.S. Code § 523(a)(1) y (14)). En Francia, las deudas derivadas de maniobras fraudulentas en perjuicio de organismos de seguridad social (art. L711-4 Code de la consommation); Italia (art. 142(b), Legge Fallimentare y 14-terdecies (3)c Legge 27 gennaio 2012).
}

${ }^{44}$ WB (2014), §379. Entre otros países con esa regla: Escocia (sec. 185, Bankruptcy Act 2016); Italia (art. 142(b), Legge Fallimentare); Canadá (sec. 178(1)(g) Bankruptcy and Insolvency Act); USA, excepcionalmente si "impose an undue hardship on the debtor and the debtor's dependents" (11 U.S. Code $\S 523(\mathrm{a})(8))$.

${ }^{45}$ En este sentido: USA (11 U.S. Code § 1328(3)); Irlanda (sec. 2, Personal Insolvency Act 2012); Reino Unido (sec. 10.146 Insolvency Act 2016); Francia (Article L711-4(2)); Italia (art. 142(b), Legge Fallimentare y 14-terdecies (3)b Legge 27 gennaio 2012).

${ }^{46}$ Entre otros países, USA (11 U.S. Code \$523(a)(4) y (9)); Italia (arts. 142(b), Legge Fallimentare y 14-terdecies (3)b Legge 27 gennaio 2012)); Canadá (sec. 178(1)(a) Bankruptcy and Insolvency Act); ); Reino Unido (sec. 281(5)(a) Insolvency Act 1986).

${ }^{47}$ La inexigibilidad de los saldos insolutos es la regla en Colombia (art. 571.1 L. 1564/2012); Italia (art. 143.I Legge Fallimentare); USA (11 U.S. Code \$524(e)). Sobre el régimen colombiano, RodRíGuEz ESPITIA (2013), p. 385.

${ }^{48}$ La cuestión es zanjada expresamente en el sentido de subsistir la garantía, aun cuando la obligación principal se extinga en virtud del discharge en Alemania (\$301.2 Insolvenzordnung); Escocia (Bankruptcy Act 2016, sec. 145.5 y 206); Nueva Zelandia (sec. 306 Insolvency Act 2006): Irlanda (sec. 46 Personal Insolvency Act 2012); Canadá (sec. 179 Bankruptcy and Insolvency Act); Italia (art. 142 in fine); 
Como se puede apreciar de esta descripción general, el discharge aparece como una figura cuyos contornos varían en los distintos ordenamientos estudiados, reflejando la sensibilidad local frente al fenómeno del sobreendeudamiento, aunque existe un núcleo común: la necesidad de dispensar una tutela especial al deudor persona natural mediante la alteración de las reglas del derecho común. De esta forma, el derecho concursal del consumidor adquiere una fisonomía propia, según se explicará en el apartado siguiente.

\subsection{El discharge como un cambio de paradigma: los fines del derecho concursal del consumidor}

La incorporación de una regla de exoneración legal de los saldos insolutos tras el concurso del deudor-consumidor implica un cambio de paradigma de la disciplina concursal tradicional, tanto desde la perspectiva de los intereses tutelados (2.2.1), como respecto a la función del concurso en un ordenamiento jurídico (2.2.2).

\subsubsection{La tutela (preferente) del interés del consumidor}

La incorporación de una regla de extinción legal de los saldos insolutos de la persona deudora constituye un cambio de signo en la lógica concursal, pasando de servir (exclusivamente) a los intereses de los acreedores, a tutelar (preferentemente) el interés del consumidor ${ }^{49}$.

Esta transformación queda bien demostrada al analizar la evolución de la propia regla de discharge. Como es bien sabido, el origen de esta figura se encuentra en Inglaterra, el año 1705, al promulgar el Parlamento un Statute de la Reina Ana, que establecía -en lo que ahora más interesa-, la liberación del deudor honesto y cooperador de las deudas previas al procedimiento de insolvencia si obtenía un certifícate of conformity emitido por una comisión concursal y (a partir de 1706, adicionalmente, si obtenía) el consentimiento de los acreedores. La finalidad de la regla (coherente con el resto de la legislación concursal) tuvo como propósito dar un nuevo instrumento a los acreedores para mejorar sus posibilidades de cobro. Así queda de manifiesto al establecerse que la comisión debía tomar en consideración para emitir el certificado de conformidad, entre

Colombia (art. 571.1 L. 1564/2012); USA (11 U.S. Code \$524(e), donde es una injuction, que en el marco de un procedimiento concursal de liquidación no favorece a terceros, sino solamente al deudor: Boyle (1992), pp. 429 y 239; Brubaker (1997), p. 969; Gamble (2011), p. 847). En Francia, la Corte de Casación ha sostenido que el discharge no extingue la obligación, sino solamente suprime el derecho de acción (Ruz LÁRTIGA (2017), p. 1256).

${ }^{49}$ Por muchos, JACKSON (1986), pp. 226-227. 
otros aspectos, la colaboración del deudor en la puesta a disposición de todos sus bienes y de la información sobre sus negocios (buena fe $)^{50}$.

No fue hasta la Bankruptcy Act de 1841, en los Estados Unidos de América (y a consecuencia de la crisis económica de 1837), que el discharge comenzó a adquirir la fisonomía actual pro debitoris. Ese cambio tuvo lugar a consecuencia de la introducción de ciertas reformas concursales generales -la expansión del procedimiento concursal a todo deudor (no sólo a los comerciantes) y el inicio de éste de forma voluntaria por el deudor-y otra, en particular, respecto de la exoneración legal de los saldos insolutos: la limitación de la facultad de los acreedores de oponerse al discharge (aunque como contrapeso, se aumentaron las causales para denegar judicialmente este beneficio, por ejemplo, sólo se concedía una segunda vez, si se pagaba el 75\% de los créditos). Las características contemporáneas de la exoneración legal de deudas quedan definitivamente plasmadas sólo a partir de la Bankruptcy Act de 1898, al eliminarse el consentimiento de los acreedores como requisito de la misma ${ }^{51}$.

Desde una perspectiva sistémica, el carácter pro debitoris de la regla de discharge significa un cambio de la función del derecho concursal. Tradicionalmente, el cometido asignado al concurso es la tutela del crédito ${ }^{52}$; éste se logra por medio de un procedimiento de ejecución colectiva universal orientado a maximizar la recolección de pagos por parte de todos los acreedores. La protección del crédito como idea secular orientadora del régimen concursal queda bien demostrada al examinar la distribución de poder al interior del concurso: el poder de disposición sobre los bienes del deudor afectos al concurso sale de la esfera de decisión del deudor y queda en manos de los acreedores (en nuestro ordenamiento, además, en forma exclusiva; artículo 207 NLC) ${ }^{53}$. Desde un punto de vista económico, esta distribución de poder al interior del concurso es coherente con la condición de residual owners de los accionistas: éstos sólo tienen derecho a las utilidades o al reembolso de los aportes una vez satisfechas las deudas sociales (exigibles) ${ }^{54}$. Dado que en un procedimiento concursal de liquidación, usualmente, el patrimonio del deudor no alcanza para cumplir con las deudas, el carácter residual de los derechos de los accionistas pasa a un

\footnotetext{
${ }^{50}$ TABB (1991), pp. 333-339. La exoneración legal de deudas fue el contrapunto (la zanahoria) de un endurecimiento de la responsabilidad del quebrado, al establecer -también este estatuto- la pena de muerte (el garrote) para el deudor concursal fraudulento (TABB (1991), pp. 337).

${ }^{51}$ ТАвB (1991), pp. 349-352.

${ }^{52}$ Jackson (1986), p. 5; Gómez y Eyzaguirre (2011), p. 51; Puga Vial (2014), pp. 45 y 50.

${ }^{53}$ Puga Vial (2014), p. 531.

${ }^{54}$ JeNSEN Y MECKLING (1976), p. 311. Idea también recogida en el art. 117.I LSA.
} 
primer plano, al reconocerse a los acreedores el referido poder de disposición sobre los bienes afectos al concurso como mecanismo de tutela del crédito.

La orientación tradicional pro creditoris del concurso pierde vigor tratándose de un consumidor. La protección de la persona natural sobreendeudada por medio de la extinción de los saldos insolutos aparece como el pilar fundamental del derecho concursal del consumidor, cuyas consecuencias impactan en la comprensión del derecho de obligaciones. Conforme al derecho común, el término de una ejecución o de un procedimiento concursal, no extingue las deudas pendientes de pago, conservando los acreedores las acciones para el cobro de las mismas si el deudor mejora su situación económica (garantía general patrimonial). En esas circunstancias, una persona sobreendeudada, cuyos bienes afectos al concurso han sido repartidos entre sus acreedores concursales, tiene nulos incentivos para reinsertarse en la actividad económica, pues los eventuales futuros beneficios serán también capturados por sus actuales acreedores. De esta forma, los problemas económicos, de salud y familiares (supra 1.3) vinculados al sobreendeudamiento se agravan y perpetúan, impidiendo al deudor desarrollarse plenamente y a la comunidad beneficiarse del potencial creativo de esa persona. La regla de discharge de un consumidor tiene como finalidad brindar al deudor la posibilidad de iniciar nuevamente una actividad productiva y generar ingresos suficientes para cubrir los gastos personales y familiares, libre de las cargas crediticias excesivas previas al inicio del procedimiento concursal ${ }^{55}$.

La tutela preferente del interés del deudor no significa excluir por completo de atención el interés de los acreedores. En muchas ocasiones, la exoneración legal de los saldos insolutos sólo reflejará la realidad: los créditos cobrados representan una ilusión a consecuencia de carecer el deudor de bienes afectos al concurso ${ }^{56}$. En esas circunstancias, la regla de discharge evita prolongar una situación insuperable para el deudor, ahorrando a los acreedores los gastos concursales y al Estado los derivados de la actividad jurisdiccional o administrativa, según el caso. Una manifestación de lo anterior en nuestro ordenamiento

\footnotetext{
${ }^{55}$ W $(2014), \S 3 ; 51 ; 99$ y 106. La entidad subraya que las reglas de insolvencia no son una herramienta adecuada para combatir la pobreza: "An insolvency regime serves mainly individuals who do not suffer from a long term disability or general surfeit of resources and who thus do not need affirmative social support. Insolvency regimes are designed primarily and work best for individuals who are capable of producing sufficient income to support themselves and their families, but an overwhelming debt burden saps their initiative and depresses their productive capacity. These debtors do not seek more government intervention in their lives; they seek less government intervention from officially sanctioned wasteful and destructive debt enforcement action. The goal is to stop counterproductive debt collection, not to receive financial or other resources" (WB (2014), §36).
}

${ }^{56}$ WB (2014), §38. 
es el derecho de un acreedor a castigar como crédito incobrable para efectos tributarios los saldos insolutos de las deudas anteriores al inicio del procedimiento concursal una vez firme la resolución de término ${ }^{57}$.

\subsubsection{El carácter redistributivo del discharge}

La incorporación de una regla de exoneración legal de las deudas insolutas implica asignar al concurso de una persona natural una función redistributiva de las pérdidas ocasionadas por el sobreendeudamiento ${ }^{58}$. Se ha sostenido que ese efecto redistributivo implica asignar al régimen de insolvencia del consumidor una función de seguro (social) protegiendo al consumidor frente al sobreendeudamiento ${ }^{59}$. Desde esta perspectiva, el discharge asigna a los acreedores parte del riesgo de sobreendeudamiento del consumidor insolvente, a cambio de un incremento del costo del crédito (prima) ${ }^{60}$. Al igual que un incendio o un accidente automovilístico -se afirma- el excesivo endeudamiento depende de causas usualmente previsibles, pero inevitables (pérdida del empleo y enfermedad, entre las más frecuentes; supra 1.2). En esas circunstancias, no tiene sentido concentrar la pérdida en el consumidor sobreendeudado, sino que es preferible repartirla entre los acreedores, quienes, ex ante, están en mejor posición para gestionar ese riesgo, no sólo por medio de una concesión responsable de crédito, sino también dispersando esa pérdida en la comunidad (por ejemplo, a través del aseguramiento de la cartera crediticia o transfiriéndola a sus accionistas). Las entidades financieras pueden mitigar el riesgo de sobreendeudamiento del deudor a través del desarrollo de políticas de crédito prudentes en sustitución de modelos de negocio agresivos, con alto riesgo y altas tasas de retorno. En suma, se trata de equilibrar los positivos efectos para la sociedad de un mayor acceso al crédito por parte de los consumidores con los riesgos del sobreendeudamiento, que para muchos de ellos resultan inevitables o incomprensibles ${ }^{61}$.

\footnotetext{
${ }^{57}$ Servicio de Impuestos Internos, Circular N 62, de 18 de octubre de 2016, sección III.2.B.

${ }^{58}$ WB (2014), §88-98, a quien seguimos en este párrafo.

${ }^{59}$ WB (2014), §35 y 95; Kilborn (2008), p. 595; Ramsay (2017), pp. 9 y 156.

${ }^{60}$ WB (2014), §96-97; FEIBELMAN (2005), p. 142. Este autor entiende un seguro social como un programa en el cual los costos del beneficio son soportados, directa o indirectamente, por el beneficiado. En cambio, un programa de asistencia social se focaliza en quienes lo necesitan, sin considerar pagos (Feibelman (2005), p. 138).

${ }^{61}$ En sentido similar Ruz LÁrtiga (2017), p. 1277. Bajo este esquema de distribución del riesgo de sobreendeudamiento, la falta de un bureau de crédito, con información sobre el comportamiento (positivo y negativo) de un deudor, es un vacío sensible para el buen funcionamiento del sistema vigente. Un bureau de crédito podría mitigar la externalidad negativa de la regla de exoneración legal de los saldos insolutos de la "desbancarización" de los grupos con mayor riesgo de sobreendeudamiento.
} 
La visión del discharge como una forma de seguro tiene la virtud de iluminar algunas de sus patologías, entre ellas, el riesgo moral: la exoneración legal de las deudas insolutas puede generar incentivos en ciertos deudores para endeudarse sin necesidad y por sobre sus posibilidades reales, con la perspectiva de liberarse de las deudas, sin pagarlas ${ }^{62}$. No es necesario insistir en las nefastas consecuencias para la fluidez del crédito si ese fuera un comportamiento generalizado. Una forma de mitigar el riesgo moral es fijar unos requisitos de acceso al discharge capaces de desincentivar un mal uso de este beneficio, un problema sensible en nuestro ordenamiento, a cuyo estudio dedicamos los apartados siguientes.

\section{El discharge en el procedimiento concursal de la persona deudora: ¿cómo estamos por casa?}

El acceso al crédito de los chilenos en las últimas décadas ha experimentado un rápido crecimiento, como lo demuestra el fuerte desarrollo del mercado de las tarjetas de crédito, en particular, de casas comerciales (supra 1.1). Los efectos positivos de este crecimiento se ven empañados, sin embargo, con un simultáneo incremento del sobreendeudamiento por parte de los consumidores, especialmente marcado en los hogares con ingresos más bajos (supra 1.2). En ese contexto, la aprobación de una regla de discharge en el marco de un procedimiento concursal de una persona deudora es, a priori, una buena noticia. Sin embargo, nos interesa contrastar los rasgos de la regulación patria con las tendencias observadas en el derecho comparado (3.1) y, posteriormente, evaluar hasta qué punto la regulación vigente constituye una novedad en nuestro ordenamiento (3.2).

\subsection{La fisonomía de la regla}

La exoneración legal de los saldos insolutos en nuestro ordenamiento presenta marcadas diferencias con las tendencias observadas a nivel internacional (supra 2.1), como puede apreciarse de la escueta formulación de la regla en estudio ${ }^{63}$ :

"Una vez que se encuentre firme o ejecutoriada la resolución que declara el término del Procedimiento Concursal de Liquidación, se entenderán extinguidos

\footnotetext{
${ }^{62}$ WB (2014), §113-115.

${ }^{63}$ La exoneración legal de las deudas insolutas respecto del consumidor se establece para dos supuestos de hecho: al término de un procedimiento concursal de renegociación en virtud de un acuerdo de ejecución (art. 268.II NLC) y al finalizar un procedimiento concursal de liquidación de una persona deudora por medio de la dictación de una resolución de término (art. 281 en relación al art. 255 $\mathrm{NLC}$. Este estudio abarca principalmente el procedimiento concursal de liquidación de bienes de una persona deudora y sólo nos referiremos ocasionalmente al procedimiento concursal de renegociación.
} 
por el solo ministerio de la ley y para todos los efectos legales los saldos insolutos de las obligaciones contraídas por el Deudor con anterioridad al inicio del Procedimiento Concursal de Liquidación" (artículo 255.I LC).

El único rasgo coincidente con la práctica internacional mayoritaria es la opción de nuestros legisladores por el efecto extintivo del discharge. La característica particular de la exoneración legal como modo de extinguir las obligaciones (extravagante a los enumerados en el artículo 1567 Cc.) es su carácter personal: se trata de un beneficio legal otorgado en razón del sujeto insolvente y exclusivamente a su favor. De allí que los terceros no puedan invocar el discharge en su beneficio, según se desprende de los antecedentes patrios de la regla, expuestos en la sección 3.2. siguiente.

Nuestros legisladores no consideraron oportuno, no obstante los antecedentes y prácticas existentes a nivel comparado, exigir para la concesión de la exoneración legal, una conducta honesta del deudor, a fin de reducir el riesgo moral. Tampoco se contempla la necesidad de cumplir con un plan de pagos acordado entre el deudor y los acreedores, ni se establecieron reglas especiales respecto de los deudores "NINA" ${ }^{64}$. Como antes se indicó, la exoneración legal de los saldos insolutos en nuestro ordenamiento opera automáticamente (automatic discharge), sin necesidad de una resolución fundada, no obstante ser esta última la práctica mayoritaria en el derecho comparado. La sujeción del deudor a cursos básicos de formación financiera destinados a contribuir a un cambio de hábitos en el manejo de sus finanzas no es tampoco un requisito del discharge, a lo que se suma la posibilidad de un deudor de obtener este beneficio en más de una oportunidad ${ }^{65}$. En fin, tampoco nuestros legisladores han considerado oportuno explicitar las deudas que deben entenderse exceptuadas del discharge, aunque ello sea una práctica uniforme en todos los ordenamientos estudiados.

Como se puede apreciar, existe una notable brecha entre la regulación nacional y los estándares internacionales, lo cual -en buena parte- permite explicar los graves problemas presentes en la aplicación del discharge por parte de nuestros tribunales, según veremos más adelante (infra 4). Antes de ello es útil preguntarnos cuáles pueden haber sido las razones para abordar el problema

\footnotetext{
${ }^{64}$ Un plan de pagos vinculado al discharge no está contemplado ni siquiera en el llamado "acuerdo de ejecución" en el marco de un procedimiento de renegociación (art. 267 NLC).

${ }^{65}$ Una excepción podría encontrarse en el marco de un acuerdo de ejecución. Éste se enmarca dentro de un procedimiento de renegociación de una persona deudora, el cual puede (volver a) iniciarse una vez transcurridos cinco años contados desde la fecha de publicación de la resolución de admisibilidad (art. 270.III NLC). Por lo anterior, esa restricción (directa) de una persona deudora para solicitar nuevamente la apertura de un procedimiento de renegociación puede entenderse como una limitación temporal (indirecta) al discharge fruto de un acuerdo de ejecución.
} 
del sobreendeudamiento en la NLC en los términos antes expuestos, a lo que dedicamos la sección siguiente.

\subsection{La exoneración legal de los saldos insolutos: ¿continuidad o quiebre de la tradición concursal patria?}

La novedad del favor debitoris en el concurso de una persona deudora puede ser puesta en duda en nuestro ordenamiento. La extinción de los saldos insolutos del deudor persona natural sujeto a un procedimiento concursal de liquidación fue introducida, por primera vez en nuestro ordenamiento, el año 1929 - durante el primer mandato presidencial de Carlos Ibáñez del Campo, en los términos siguientes:

"Se sobreseerá también definitivamente, aun cuando las deudas no se hubieren alcanzado a cubrir con el producto de la realización de todos los bienes de la quiebra, siempre que concurran los siguientes requisitos:

1.- Que hayan transcurrido cinco años contados desde que hubiere sido aprobada la cuenta general del síndico;

2.- Que, habiendo terminado el procedimiento de calificación de la quiebra del deudor comerciante, por sentencia ejecutoriada, la quiebra haya sido calificada de fortuita y si se tratare de un deudor no comerciante que no haya sido condenado por alguno de los delitos contemplados en el artículo 466 del Código Penal.

El sobreseimiento de que trata este artículo extingue, además, las obligaciones del fallido por los saldos insolutos de sus deudas anteriores a la declaración de quiebra, sin perjuicio de distribuirse entre los acreedores el producto de los bienes adquiridos con posterioridad y ya ingresados a la quiebra, con arreglo al artículo 62 de la presente ley" (artículo 134 de la Ley $\left.N^{\circ} 4558\right)^{66}$.

\footnotetext{
${ }^{66}$ Las ideas subyacentes al establecimiento de la exoneración legal de los saldos insolutos derivado del sobreseimiento definitivo de la quiebra de una persona natural, aparecen bien delineadas en las palabras del propio Mensaje de la Ley $N^{\circ} 4558$, que no nos resistimos a transcribir in extenso:"[p] ero el sobreseimiento definitivo irá más lejos y extinguirá en ciertos casos las obligaciones del deudor. Esta novedad, que tal vez parezca atrevida e inconsiderada, responde a un sentimiento de justicia y a un propósito de bien público.//La quiebra es un juicio que tiende a favorecer los intereses particulares perjudicados y a satisfacer la compensación que debe al crédito público el deudor que ha faltado al cumplimiento de sus compromisos; empero, es prudente, humanitario y justo no extremar estas medidas hasta el exagerado rigor. No siempre el fallido ha llegado a su infortunio merced a la culpa o al fraude; muchas veces han sido casualidad y los reveses del destino los que han arrastrado al incumplimiento de sus obligaciones. Y entonces, su condición reclama benignidad, porque necesita mirar el porvenir con confianza y estímulo para que pueda emprender de nuevo el camino del esfuerzo y quizá del éxito. Porque hay que tener presente que es el fallido de quiebra fortuita, que no ha conseguido pagar todas sus deudas, al que protegerá en el hecho la medida adoptada.//La sociedad, sobre todo un pueblo joven y en formación, debe cuidar que sus sanciones para con el deudor inocente no se transformen
} 
Tras la derogación de la Ley $N^{\circ}$ 4558, el texto legal antes transcrito fue conservado, en términos casi idénticos, en el artículo 165 de la Ley № 18.175, más tarde incorporado con igual numeración en el Libro IV del Código de Comercio. De esta forma, la norma se mantuvo vigente en nuestro país por más de 80 años, hasta la entrada en vigor de la nueva ley concursal ${ }^{67}$.

En nuestra opinión, el único rasgo común entre la regla derogada y la vigente es el carácter personal del discharge bien expresado en las palabras del Mensaje de la Ley $N^{\circ}$ 4558: la finalidad de la exoneración legal es salvar del "escepticismo y la desidia" al deudor insolvente tras liquidarse todos sus bienes afectos al concurso, por ser ello "prudente, humanitario y justo". Esa idea se refleja en el texto vigente al circunscribir el efecto extintivo a "las obligaciones contraídas por el Deudor", en concordancia con el texto y el espíritu de la regla derogada de beneficiar exclusivamente al deudor (insolvente) y no a terceros (solventes) ${ }^{68}$.

Las diferencias más notables entre la regla de discharge vigente y el texto (octogenario) derogado son las siguientes: i) en la NLC la exoneración se produce inmediatamente de quedar firme la resolución de término (acortándose drásticamente el plazo, antes fijado en cinco años contados desde que hubiere sido aprobada la cuenta definitiva del síndico); ii) se elimina la exigencia de tratarse de una quiebra fortuita (que bajo el régimen anterior implicaba un expediente

en un arma que hiera su propio interés, porque el escepticismo y la desidia de los caídos de ahora puede restar más tarde valores de importancia al progreso nacional.//Por lo demás, los hechos han comprobado que, después de liquidada una quiebra, los acreedores han sido reembolsados en el saldo apenas en casos excepcionalísimos y ese reembolso no ha sido el resultado de la coacción, sino de la voluntad espontánea del deudor que paga" (Bravo Kendrick (1929), p. XIV). La sintonía de los legisladores patrios del siglo pasado con las actuales tendencias del derecho concursal es destacable. La causa de esa convergencia es que tanto los efectos del sobreseimiento definitivo de la Ley $\mathrm{N}^{\circ} 4558$ como el discharge actualmente en auge se fundan en ideas comunes: la protección del deudor honesto, pero desafortunado, mediante la extinción de los saldos insolutos (Bravo RodríGuez, (1940), pp. 39-47).

${ }^{67}$ Ley $N^{\circ} 18.175$, publicada en el Diario Oficial de 28 de octubre de 1982. La redacción del artículo 165 del Libro IV del Código de Comercio era la siguiente: "Se sobreseerá también definitivamente, aun cuando las deudas no se hubieren alcanzado a cubrir con el producto de la realización de todos los bienes de la quiebra, siempre que concurran los siguientes requisitos: 1.- Que hayan transcurrido dos años contados desde que hubiere sido aprobada la cuenta definitiva del síndico; 2.- Que, habiendo terminado el procedimiento de calificación de la quiebra por sentencia ejecutoriada, haya sido calificada de fortuita, y 3.- Que el deudor no haya sido condenado por alguno de los delitos contemplados en el artículo 466 del Código Penal.//El sobreseimiento de que trata este artículo extingue, además, las obligaciones del fallido por los saldos insolutos de sus deudas anteriores a la declaración de quiebra, sin perjuicio de distribuirse entre los acreedores el producto de los bienes adquiridos con posterioridad y ya ingresados a la quiebra, con arreglo al inciso segundo del artículo 65".

${ }^{68} \mathrm{Si}$ un tercero (por ejemplo, un codeudor solidario), a su turno, cae en insolvencia, también podrá obtener la exoneración legal de los saldos insolutos una vez terminado el propio procedimiento concursal de liquidación, pero no debe beneficiarse del discharge concedido a favor del deudor principal insolvente. 
de calificación), y iii) así como el requisito de no existir responsabilidad penal (que implicaba esperar el término de un juicio penal) ${ }^{69}$.

En los antecedentes legislativos de la NLC no existe rastro de las razones para un cambio de esta magnitud ${ }^{70}$. Entendemos que este cambio significativo se realizó con la pretensión de mejorar la posición de Chile en el ranking Doing Business, uno de los objetivos explícitos de la NLC: se sostuvo que el promedio de duración de un procedimiento concursal en nuestro país alcanzaba los 4,5 años, en comparación 1,7 años de promedio en los países de la OCDE71. De acuerdo al Mensaje, el procedimiento concursal era lento, de larga tramitación, siendo necesario realizar "cambios radicales" para rebajar su duración, pues ello afectaba negativamente la competitividad del país para realizar negocios. La simplificación del supuesto de hecho de la exoneración legal de los saldos insolutos es una de las varias reformas "radicales" destinadas a disminuir la duración de un procedimiento concursal ${ }^{72}$. Esto explica (aun cuando no convenza) la exclusión de cualquier elemento del supuesto de hecho del discharge capaz de extender la duración del concurso (como, por ejemplo, en relación al régimen previo, la calificación de la quiebra fortuita o la inexistencia de delitos concursales; o, en relación a los estándares actuales en el derecho comparado, la calificación de la honestidad del deudor; la sujeción a un plan de pagos; la asistencia a cursos de formación financiera básica; o la necesidad de una resolución fundada para el otorgamiento del beneficio legal). En suma, lo relevante a los efectos de esta investigación es que la nueva regulación de la exoneración legal de los saldos insolutos no fue diseñada atendiendo a la experiencia recogida en otros ordenamientos ni a los complejos problemas sustantivos presentes en esta institución (supra 1), sino con la atención puesta

\footnotetext{
${ }^{69}$ Otro cambio significativo, aunque ajeno al ámbito de este trabajo es el hecho de haberse ampliado el ámbito de aplicación subjetivo de la norma, abarcando no sólo una persona natural (lo cual se desprende en la ley derogada de la referencia a la ausencia de responsabilidad penal) sino también a una empresa deudora, lo cual, sin embargo, queda fuera del objeto de este trabajo, según antes indicamos.

${ }^{70}$ El punto no pasó desapercibido durante la tramitación parlamentaria. Consta en actas que el profesor Rafael Gómez Balmaceda hizo presente la inconveniencia de estos cambios, no obstante lo cual el artículo fue aprobado sin discusión (Historia de la Ley, p. 2182).

${ }^{71}$ Historia de la Ley, Mensaje Presidencial, pp. 9, 210 y 398. Una visión crítica acerca del diagnóstico del Gobierno sobre el plazo de duración del procedimiento concursal fue expuesta durante la tramitación legislativa, por el profesor Juan Esteban PUGA VIAL (Historia de la Ley, p. 1934).

${ }^{72}$ Otras son los plazos brevísimos, la limitación de los incidentes y de los recursos. En este sentido, se ha sostenido que la "economía procesal y la celeridad" son "principios formativos" de la NLC (CONTADOR Y PAlacios (2015), pp. 44-46).
} 
en el plazo de duración de los procedimientos concursales (y la eventual mejora en el ranking Doing Business) ${ }^{73}$.

Por todo lo anterior, en nuestra opinión, las divergencias apuntadas impiden afirmar una continuidad con el régimen derogado, tanto por razones del contexto (regulación de un procedimiento concursal específico para consumidores ${ }^{74}$ ) como de la configuración de la regla (excesiva simplificación del supuesto de hecho). La ausencia de un plazo y la rebaja de los requisitos subjetivos cambian a tal punto la fisonomía de la regla de exoneración que no puede afirmarse una continuidad. Bajo la ley concursal previa, la exoneración de los saldos insolutos desempeñaba un papel secundario, pues operaba tras un largo plazo y cumplidos ciertos requisitos legales, todo lo cual disminuía su impacto tanto para el deudor como para los acreedores. En ese escenario, la amplitud del efecto extintivo no solía producir conflictos: transcurrido el plazo legal existía menos interés de los involucrados en la suerte del deudor ${ }^{75}$. Por lo mismo, así concebida la referida regla, tampoco incentivaba al deudor a iniciar un procedimiento concursal con miras a obtener la exoneración legal de los saldos insolutos como objetivo principal, pues -vale la pena insistir-se trataba de una consecuencia lejana en el tiempo y dirigida a un grupo restringido de deudores. En la actualidad, el discharge aparece como el núcleo central de la protección del consumidor insolvente, dada su automática consecución en el marco de un procedimiento concursal de liquidación de una persona deudora. Este cambio radical ha incentivado a los consumidores no sólo a iniciar más procedimientos concursales, sino a preferir la liquidación por sobre la renegociación ${ }^{76}$. De

\footnotetext{
${ }^{73}$ Aunque puede ser prematuro sacar conclusiones definitivas, de acuerdo al informe Doing Business 2017 (elaborado con datos recogidos el año 2016), la duración promedio de un procedimiento concursal en Chile alcanza 3,2 años; bastante menos que 4,5 años, pero también bastante más que 1,7 años, el promedio OCDE (WB (2016), p. 1).

${ }^{74}$ Contador y Palacios (2015), pp. 29-30.

${ }^{75}$ Puga Vial (2014), p. 645.

${ }^{76}$ La preferencia por la reorganización como mecanismo para resolver la insolvencia por sobre la liquidación quedó de manifiesto durante la tramitación de la ley al considerarse la liquidación como la "última ratio" y la reorganización como la materia central de la nueva ley, justificando, además, por esa razón la dependencia de la Superintendencia de Insolvencia y Reemprendimiento al Ministerio de Economía y no al de Justicia, como su antecesora (Historia de la Ley $N^{\circ} 20.720$, p. 2244). Bajo el régimen previo, anualmente se iniciaban, en promedio, 175 procedimientos de quiebra; en cambio, bajo la NLC, solamente los procedimientos concursales de liquidación de la persona deudora, cuadruplicaron esa cifra durante el año 2016. Si bien el diseño legal pretendía convertir a la renegociación en la forma ordinaria de resolver una insolvencia (Historia de la Ley $N^{\circ}$ 20.720, Mensaje, p. 7; críticamente, PugA VIAL, Liquidación, p. 176), las cifras muestran una tendencia distinta: si bien durante el años 2015 se iniciaron 894 procedimientos de renegociación y 281 de liquidación de la persona deudora, el año 2016, se iniciaron 994 procedimientos de renegociación y 1.175 de liquidación de la persona deudora. Esta tendencia alcista en los procedimientos de liquidación se mantiene a la vista de las cifras del año
} 
allí que algunos han considerado esta práctica como un abuso por parte de ciertos consumidores, cuyo actuar temerario es aparentemente avalado por la generosidad del régimen concursal vigente ${ }^{77}$. El discharge aparecería como un subterfugio para evadir el cumplimiento de obligaciones plenamente válidas. Una triquiñuela.

La nueva regla de exoneración legal de los saldos insolutos se aleja de nuestra tradición concursal sin una justificación plausible, aumentando innecesariamente los incentivos para un comportamiento financiero descuidado por parte de los consumidores (riesgo moral) y ello es lo que está a la base de la actual "mala fama" del procedimiento de liquidación de bienes de una persona deudora. En ese contexto se deben enmarcar las reacciones "correctivas" de las instituciones judiciales y administrativas a cargo de conducir la tramitación del procedimiento concursal de un consumidor, según se explicará en el apartado siguiente.

\section{Las medidas correctivas de origen administrativo y judicial}

La negativa percepción sobre la actual regla de discharge automático ha motivado reacciones "correctivas" por parte de autoridades administrativas y judiciales. Los mecanismos ensayados son, por una parte, impedir el inicio del concurso (4.1) y, por otra parte, la exclusión de ciertos créditos del concurso (4.2), según se expondrá en los apartados siguientes.

\subsection{La inadmisibilidad de la solicitud de concurso}

Algunos tribunales han controlado rigurosamente la admisibilidad de las solicitudes de inicio de un procedimiento concursal de liquidación de una persona deudora. La justificación de esa rigurosidad reside, al menos parcialmente, en la dificultad de negar a un deudor la exoneración legal de las deudas una vez firme la resolución de término del concurso. El carácter automático del discharge en nuestro ordenamiento parece dejar a los tribunales poco margen de intervención, no obstante se trate-por ejemplo- de un deudor de mala fe o sujeto a responsabilidad penal concursal. Naturalmente, los tribunales no han quedado inermes ante esta situación y han buscado mecanismos para controlar el inicio del concurso voluntario de liquidación de un consumidor ${ }^{78}$.

2017: hasta julio se han iniciado 563 procedimientos de renegociación y 1090 de liquidación de la persona deudora (SIR (2017), p. 2).

77 Diario Concepción, sección economía y negocios, 28 de junio de 2017.

${ }^{78}$ No es un factor desdeñable en la reacción judicial descrita, el aumento de la carga de trabajo derivado de un eventual incremento de causas ingresadas -una materia relevante para los índices de 
Los mecanismos de control de admisibilidad han sido diversos, aunque es posible ordenarlos en dos grupos. Un primer grupo de sentencias eleva las menciones de la solicitud de inicio del concurso a de requisito para la legitimación activa del solicitante (artículo 273 NLC). En ese sentido, algunas sentencias han declarado inadmisible la solicitud de liquidación voluntaria de una persona natural por no indicarse, en la referida solicitud, los bienes de propiedad del solicitante afectos al concurso ${ }^{79}$; por no acreditarse la existencia de "juicios pendientes con efectos patrimoniales" ${ }^{\prime 80}$; o debido a la falta de individualización de los bienes excluidos de la liquidación ${ }^{81}$. En nuestra opinión, las referidas resoluciones apuntan a cuestiones formales, fáciles de sortear, si lo que se pretende es disuadir a (futuros) consumidores de (mal) utilizar el procedimiento concursal de liquidación a los fines de conseguir (exclusivamente) una exoneración legal de las deudas. Todavía más, la denegación de acceso a la justicia de aquellos consumidores carentes de bienes o con bienes de escaso valor es contraria a los propios fines del concurso de un consumidor (salvo fraude), donde, recordemos, el interés preferentemente protegido es el del deudor sobreendeudado (usualmente perteneciente a los quintiles más bajos; supra 2.2.1). En esta jurisprudencia es posible observar cómo el cambio de paradigma del concurso a

eficiencia de la administración de justicia-, si se "corriera la voz" de ser excesivamente fácil iniciar voluntariamente un procedimiento concursal de liquidación de una persona deudora y así obtener la exoneración legal de los saldos insolutos.

${ }^{79} 11^{\circ}$ Juzgado Civil de Santiago, rol № C-9380-2015, 19 de junio de $2015 ; 1^{\circ}$ Juzgado Civil de Curicó, rol № ${ }^{\circ}-1425-2015$, de 6 de julio de 2015; 23 Juzgado Civil de Curicó, rol № C-23821-2015, 11 de noviembre de 2015; $29^{\circ}$ Juzgado Civil de Santiago, rol No $\mathrm{C}-8163-2015$, de 14 de mayo de 2015; $4^{\circ}$ Juzgado Civil de Talca, rol № C-3639-2014, de 30 de abril de 2015; $2^{\circ}$ Juzgado Civil de Talca, rol $\mathrm{N}^{\circ} \mathrm{C}-257-2014,28$ de noviembre de 2015; $24^{\circ}$ Juzgado Civil de Santiago, rol № ${ }^{\circ}-11392-2016$, de 20 de mayo de 2016.

${ }^{80} 11^{\circ}$ Juzgado Civil de Santiago, rol No $\mathrm{C}-18059-2015,17$ de agosto de 2015; $5^{\circ}$ Juzgado Civil de Santiago, rol № C-24895-2015, 28 de octubre 2015; $23^{\circ}$ Juzgado Civil de Santiago, rol № C-238212015, 11 de noviembre de 2015; Corte de Apelaciones de Antofagasta, rol № 38-2016, 3 de agosto de 2016; Corte de Apelaciones de Antofagasta, rol № 37-2016, 4 de agosto de 2016; Corte de Apelaciones de Antofagasta, rol № 42-2016, 8 de agosto de 2016; Corte de Apelaciones de Antofagasta, rol № 31 2016, 8 de agosto de 2016; Corte de Apelaciones de Antofagasta, rol № $\mathrm{C}-1232-2016$, 8 de agosto de 2016; Corte de Apelaciones de Valparaíso, rol № 40-2016, 18 de agosto de 2016; Corte de Apelaciones de Antofagasta, rol № 36-2017, 10 de febrero de 2017; Corte de Apelaciones de lquique, rol № 4942017, 14 de julio de 2017. En contra, considerando que la mención de los juicios pendientes no es un requisito de admisibilidad de la solicitud de inicio de un procedimiento concursal de una persona deudora, Corte de Apelaciones de Valdivia, rol № 155-2016, 25 de abril de 2016; Corte de Apelaciones de Valdivia, rol № 387-2016, 5 de agosto de 2016; Corte de Apelaciones de Valdivia, rol № 386-2016, 8 de agosto de 2016; Corte de Apelaciones de Valdivia, rol No 635-2016, 21 de noviembre de 2016.

${ }^{81}$ Corte de Apelaciones de Talca, rol № C-2274-2015, 3 de noviembre de 2015. El solicitante indicó como bienes excluidos el inmueble donde habitaba, por no pertenecerle, y todos los bienes muebles al interior del mismo, sin singularizarlos. 
partir de la creación de un régimen particular para el consumidor, aún no ha sido aquilatado por parte de algunos tribunales; desde luego una tarea a la cual no ha contribuido el deficiente diseño de la exoneración legal de los saldos insolutos en la NLC.

Un segundo grupo de resoluciones ha rechazado la solicitud de inicio del concurso por no haberse probado la insolvencia del solicitante ${ }^{82}$. Esta actitud de los tribunales es razonable y excede el problema en estudio. La falta de claridad acerca del presupuesto objetivo del concurso es un déficit presente en todos los procedimientos regulados en la NLC. Las medidas extraordinarias previstas en cada uno de esos procedimientos se justifican precisamente en la insolvencia (actual o inminente) del deudor. Esta lógica no varía en el caso del concurso del consumidor $y$, por consiguiente, la insolvencia es un antecedente indispensable para una correcta comprensión de la figura del discharge, siendo correcto que un tribunal deniegue el inicio del concurso si no le consta la misma.

\subsection{La exclusión de ciertos créditos}

\subsubsection{La exclusión administrativa}

La Superintendencia de Insolvencia y Reemprendimiento (SIR) dictó el Oficio Circular No 1, de 23 de noviembre de 2015 (modificado por el Oficio Circular $N^{o} 3$, de 22 de noviembre de 2016), a fin de regular exclusivamente la tramitación del procedimiento de renegociación de una persona deudora, que -en lo que ahora más interesa- puede desembocar en un acuerdo de ejecución y dar lugar a la exoneración legal de los saldos insolutos (ex artículo 268.II NLC). El referido Oficio Circular, en la parte pertinente, establece:

"De acuerdo a lo establecido en el artículo $8^{\circ}$ de la Ley 20.720, las siguientes obligaciones, por su origen legal y naturaleza jurídica, resultan inconciliables con el Procedimiento Concursal de Renegociación de la Persona Deudora, por lo tanto no podrán ser invocadas como obligaciones vencidas, ni renegociadas

\footnotetext{
$822^{\circ}$ Juzgado Civil de Santiago, rol № $\mathrm{C}-23632-2015,13$ de noviembre de 2015; $24^{\circ}$ Juzgado Civil de Santiago, rol No ${ }^{\circ}-11392-2016,20$ de mayo de 2016; $1^{\circ}$ Juzgado Civil de San Miguel, rol № C-925192016, 8 de noviembre de 2016; Corte de Apelaciones de Antofagasta, rol № 38-2016, 3 de agosto de 2016; Corte de Apelaciones de Antofagasta, rol № 37-2016, 4 de agosto de 2016; Corte de Apelaciones de Antofagasta, rol № 42-2016, 5 de agosto de 2016; Corte de Apelaciones de Antofagasta, rol $N^{\circ}$ 31-2016, 8 de agosto de 2016; Corte de Apelaciones de Antofagasta, rol № civil 1232-2016, 8 de agosto de 2016; Corte de Apelaciones de Valparaíso, rol № 40-2016, 18 de agosto de 2016; Corte de Apelaciones de Antofagasta, rol № 36-2017, 10 de febrero de 2017; Corte de Apelaciones de Iquique, rol № 110-2017, de 21 de marzo de 2017; Corte de Apelaciones de Copiapó, rol № 110-2017, 21 de marzo de 2017; Corte de Apelaciones de Iquique, rol № 494-2017, 14 de julio de 2017. En contra, considerando innecesaria la prueba de la insolvencia, Corte de Apelaciones de Santiago, rol № $13434-$ 2015, 30 de marzo de 2016.
} 
en el referido procedimiento: a) Obligaciones en que el solicitante del referido procedimiento, tenga la calidad de fiador, codeudor o aval y no de deudor principal. b) Pensiones alimenticias atrasadas o futuras, de acuerdo a la Ley $N^{\circ}$ 14.908. c) Compensación económica, de acuerdo a lo establecido en la Ley No 19.947. d) Cotizaciones previsionales de los trabajadores que hubieren estado bajo la dependencia de la Persona Deudora y las cotizaciones previsionales legales de la Persona Deudora, de acuerdo al Decreto Ley No 3.500. e) Multas impuestas por Órganos de la Administración del Estado y Juzgados de Policía Local, de acuerdo a lo establecido en las respectivas leyes. f) Obligaciones provenientes de créditos con aval del Estado que no sean aún exigibles, de conformidad al artículo 12 de la Ley No 20.027" (artículo 2.3 Oficio Circular No 1 SIR).

El objetivo de la regla transcrita es doble: se pretende, por una parte, impedir renegociar ciertos créditos y, por otra parte, blindarlos frente al (eventual) discharge (derivado de un acuerdo de ejecución). En efecto, el listado de créditos antes transcrito presenta notables coincidencias con el listado de créditos excluidos del discharge en otros ordenamientos (supra 2.1.v). Esa coincidencia nos parece un indicio suficiente de la intención de la SIR de limitar (también) los efectos de la exoneración legal de los saldos insolutos, vía un acuerdo de ejecución, a través de la eliminación de ciertos créditos del procedimiento concursal de renegociación ${ }^{83}$.

Además de ser discutible si la SIR tiene facultades legales para excluir ciertos créditos del procedimiento de renegociación, en nuestra opinión, el referido listado produce ciertas consecuencias nocivas respecto del discharge. Por una parte, la exclusión sólo tendrá efecto en el supuesto de exoneración legal vinculado a un acuerdo de ejecución. Esto produce, al menos, dos efectos indeseados: i) ciertos créditos quedarán excluidos de la exoneración legal dependiendo si éste se produce a consecuencia de un procedimiento concursal de renegociación o de liquidación, lo cual carece de justificación, y ii) dado que el discharge abarca un universo de créditos mayor en un procedimiento de liquidación de un consumidor, la propia SIR genera un incentivo a favor de la liquidación concursal por sobre la renegociación, precisamente el efecto contrario al pretendido por la $\mathrm{NLC}^{84}$. Por otra parte, la referencia al "origen legal y naturaleza jurídica" de las

\footnotetext{
${ }^{83} \mathrm{Si}$ bien un crédito excluido no queda sujeto al procedimiento de renegociación, debe ser informado por la persona deudora, especialmente para el supuesto de un acuerdo de ejecución, siempre sujeto a las reglas de prelación de créditos (art. 2.3 in fine, Oficio Circular SIR No 1). Dado que un crédito excluido puede ser también privilegiado (por ejemplo, las cotizaciones previsionales en los términos del art. 2471 № 5 Cc.), el acuerdo de ejecución debe considerarlo a fin de respetar las referidas reglas de prelación, sin que ello signifique que, de quedar un saldo insoluto, éste se extinga en virtud de la exoneración legal.

${ }^{84}$ Diario Concepción, sección economía y negocios, 28 de junio de 2017.
} 
obligaciones listadas es oscura. Ni están todas las obligaciones de origen legal (como, por ejemplo, los impuestos) ni se puede precisar cuál es la naturaleza jurídica común entre una fianza y un crédito universitario capaz de justificar su exclusión del procedimiento de renegociación y, en lo que ahora interesa, del acuerdo de ejecución. En fin, tampoco esa justificación nos da luces para entender por qué se omiten otras obligaciones (por ejemplo, las deudas nacidas de una acción dañosa cometida dolosamente por el deudor).

\subsubsection{La exclusión judicial}

Los tribunales han debido resolver si ciertos créditos deben quedar comprendidos en el concurso de un consumidor, precisamente, a fin de evitar la muy probable exoneración legal de los mismos una vez terminado el mismo. En concreto, algunos acreedores han solicitado la exclusión del crédito universitario con garantía del Estado (coloquialmente conocido como crédito con aval del Estado, CAE) sosteniendo que la exoneración legal de los saldos insolutos como efecto de la resolución de término ejecutoriada es incompatible con las reglas de cobro establecidas en la Ley $N^{\circ} 20.027$, sobre financiamiento de estudios de educación superior.

La controversia se ha planteado ya varias veces a los tribunales y ante la Corte Suprema, la cual, conociendo de recursos de casación en el fondo, se ha pronunciado a favor de la exclusión del crédito CAE del procedimiento concursal de liquidación de un consumidor ${ }^{85}$. Nuestro máximo tribunal sostuvo que existe una antinomia entre la NLC y la Ley No 20.027 y ésta debe resolverse conforme al criterio de especialidad, debiendo primar esta última norma: no sólo porque "los estudiantes que acceden a un crédito con garantía estatal destinado a financiar su educación superior constituyen un grupo de deudores particulares", sino también "muy especialmente [por] la regulación contenida en la citada ley [Ley No 20.027] para el caso de que el deudor no pague el crédito, relativa a los mecanismos para exigir el pago previstos en su título $V^{\prime \prime 86}$.

No interesa ahora realizar un comentario detallado de la sentencia antes referida, sino destacar los defectos del diseño legislativo. No obstante el carácter

\footnotetext{
${ }^{85}$ Sentencias de la Corte Suprema, rol № 54-2017, de 13 de junio de 2017 y rol № 800-2018, de 26 de febrero de 2018. En contra de la exclusión de un crédito CAE del concurso de un consumidor se pronunció la Corte de Apelaciones de Concepción (rol № 1702-2016, 3 de febrero de 2017) y la Corte de Apelaciones de San Miguel (rol No 1702-2016, 7 de diciembre de 2016, casada por la sentencia de la Corte Suprema referida en el cuerpo del trabajo). A favor de la exclusión se pronunció la Corte de Apelaciones de Santiago (rol № 10521-2016, 15 de noviembre de 2016, con voto disidente).

${ }^{86}$ Similares consideraciones se expresan en la sentencia de la Corte Suprema, rol № 4656-2017, 29 de mayo de 2017, considerando $9^{\circ}$, aunque por tratarse de una empresa deudora (persona natural), queda fuera del objeto de estudio del presente trabajo.
} 
perentorio de la NLC: "se entenderán extinguidos por el solo ministerio de la ley y para todos los efectos legales los saldos insolutos" (artículo 255 NLC, cursiva agregada ${ }^{87}$ ), la ausencia de límites frente a situaciones cuya tutela puede ( $y$ en algunos caso, debe) considerarse superior, deja abierta la puerta a recortar por parte de los tribunales el ámbito de aplicación de la exoneración legal de los saldos insolutos por la vía de excluir ciertos créditos del concurso (en este caso, el crédito CAE).

El mecanismo escogido para llevar adelante esa delimitación es el criterio de especialidad, contenido -según sostiene la referida sentencia- en el artículo $4^{\circ}$ Cc. y $8^{\circ} \mathrm{NLC}^{88}$. En nuestra opinión, el artículo $8^{\circ} \mathrm{NLC}$ tiene una finalidad alejada de la controversia en estudio. La función de la regla es aislar los procedimientos concursales especiales (por ejemplo, para bancos o compañías de seguros) del régimen concursal general contenido en la NLC. La Ley $N^{\circ} 20.027$ no es un procedimiento concursal y, por consiguiente, es discutible que pueda utilizarse la referida regla para zanjar la cuestión debatida: no hay ni una sola referencia en la Ley $\mathrm{N}^{\circ} 20.027$ al concurso del deudor; sólo se considera el otorgamiento de facilidades en caso de pérdida del empleo ${ }^{89}$. Aun si se aceptara existir esa antinomia, la alusión al principio de especialidad trae consecuencias indeseables respecto de otros créditos: no existe una ley "concursal" especial para excluir del concurso los créditos por alimentos o de compensación económica, de modo que siguiendo el referido criterio jurisprudencial, esos créditos deben quedar comprendidos en el concurso del consumidor y se extinguirán al quedar ejecutoriada la resolución de término si no alcanzan a ser pagados con los repartos realizados por el liquidador. Una solución, desde luego, insatisfactoria.

\section{Hacia la reconstrucción de la regla de discharge del consumidor}

\subsection{Los problemas de la regla vigente como pauta de discusión}

La regla de discharge actualmente vigente en nuestro ordenamiento presenta un grave desequilibrio en la tutela de los intereses jurídicos involucrados, cuyas manifestaciones más evidentes, en nuestra opinión, son las siguientes:

\footnotetext{
${ }^{87}$ En ese sentido la sentencias de la Corte Apelaciones de Concepción, rol № 1702-2016, 3 de febrero de 2017 y el voto disidente de la sentencia de la Corte de Apelaciones de Santiago, rol № 10521-2016, 15 de noviembre de 2016, antes citadas.

${ }^{88}$ Una idea sobre el art. $8^{\circ}$ NLC ya presente en la Historia de la Ley N 20.720 (p. 1991).

${ }^{89}$ En ese sentido, la sentencia de la Corte de Apelaciones de Concepción, rol № 1702-2016, 3 de febrero de 2017, antes citada.
} 


\section{i) La irrelevancia de la conducta del deudor}

La (excesiva) simplificación del supuesto de hecho de la regla de exoneración de los saldos insolutos rompe con la tradición concursal nacional orientada (al igual que el derecho comparado concursal contemporáneo) a proteger no al deudor a secas, sino al deudor honesto, pero desafortunado ${ }^{90}$. La conducta del deudor deber ser un elemento relevante para determinar la concesión de la exoneración legal de los saldos insolutos, pues los deudores deshonestos no merecen ser liberados de sus deudas (infra II.1). En esta misma línea, es conveniente precisar si la conducta del deudor -por ejemplo, la sujeción a programas de formación financiera básica- es relevante para determinar una futura exoneración legal de los saldos insolutos en caso de un nuevo procedimiento concursal de liquidación (una "tercera oportunidad").

\section{ii) La irrelevancia del tipo de crédito extinguido}

Para los legisladores de la NLC, aparentemente, no hay diferencia alguna entre la exoneración del saldo de una deuda cuya causa es un préstamo, un impuesto o un derecho de alimentos decretado a favor de un infante. Esa falta de ponderación de los bienes jurídicos en pugna genera una fuerte tensión al momento de aplicar la regla de discharge. No es lo mismo afectar a un acreedor profesional (como, por ejemplo, una entidad financiera) que a un infante. La cuestión de los límites de los efectos de la regla de exoneración legal amerita una profunda revisión, a fin de encontrar un adecuado equilibrio entre los intereses de todos los involucrados, muy especialmente cuando se trata de excluir créditos específicos (por ejemplo, el crédito CAE o los impuestos). El listado de créditos usualmente excluidos a nivel internacional puede servir de pauta inicial para una necesaria discusión local.

\section{iii) La irrelevancia de la situación patrimonial del consumidor}

Adicionalmente, se ha perdido la oportunidad para recoger la experiencia comparada respecto al tratamiento diferenciado de los deudores carentes de bienes (también denominados NINA). En ese caso, la solución implementada en otros ordenamientos es facilitar el discharge a través de un procedimiento breve y simplificado, específicamente adaptado a ese supuesto de hecho particular. En nuestro ordenamiento, curiosamente, el problema no es la ausencia de ese procedimiento simplificado, sino la generalidad del mismo; en otras palabras,

\footnotetext{
${ }_{90}$ Para el derecho previo, Gómez y Eyzaguirre (2011), p. 51. Respecto al derecho comparado, supra 1.2.1.i).
} 
el discharge automático establecido en la NLC bien podría servir de base para abordar la situación de los consumidores insolventes carentes de bienes, pero resulta inadecuado para abordar la situación (común) de los deudores insolventes, pero con patrimonio. En este último caso, la exoneración legal bien puede quedar sujeta a un plan de pagos o a la concesión fundada por parte del tribunal, como es la tendencia observada en el derecho comparado.

\subsection{Dos propuestas para balancear la regla vigente}

Los problemas presentes en la regla de discharge actualmente vigente ameritan una reforma legal, especialmente si se pretende excluir ciertos créditos específicos (por ejemplo, el crédito CAE) de su ámbito de aplicación, según antes indicamos. No cabe duda que esa futura reforma podrá aportar certeza frente a los problemas derivados de la excesiva simplificación de la regla vigente. Con todo, la labor de la doctrina es ofrecer una reconstrucción razonable del ordenamiento vigente a los operadores jurídicos (jueces y abogados, entre otros), al menos, en el ínterin de una anhelada reforma legal ${ }^{91}$. Este es un desafío ineludible, aun cuando se trate, como en la especie, de una tarea arriesgada. Con esa idea en mente, ofrecemos ciertas directrices interpretativas destinadas a dotar de sentido y coherencia a la regla de discharge vigente.

\subsubsection{El carácter voluntario de la obligación como límite del efecto extintivo}

El dischargetiene como finalidad permitir la reinserción de una persona natural insolvente en la actividad económica (supra 2.2.1) a través de la distribución del riesgo de sobreendeudamiento entre los acreedores (supra 2.2.2.). Esto supone el inicio de un procedimiento concursal de liquidación, agotado el cual, el deudor quedará liberado del pago de los saldos insolutos, traspasándose el riesgo de sobreendeudamiento desde el deudor-consumidor a los acreedores, pues estos últimos están en mejor posición para monitorear el comportamiento de un deudor y, por consiguiente, asumir el riesgo de sobreendeudamiento. De esta forma se incentiva un mercado crediticio dinámico y de fácil acceso para los consumidores, de la mano de políticas de concesión de crédito prudentes y equilibradas.

Conforme a lo anterior, la distinción entre acreedores voluntarios y acreedores involuntarios adquiere una relevancia particular en el contexto de la regla en estudio ${ }^{92}$. Los acreedores involuntarios son aquellos cuyos créditos

\footnotetext{
${ }^{91}$ NINO (1983), p. 326.

${ }^{92}$ La relevancia general de esta distinción en el ámbito concursal fue tempranamente destacada por el profesor Ángel Rojo, encargado de la redacción del Proyecto Anteproyecto de Ley concursal español de 1995 (DASSO (2009), p. 4) y por BeBChuk y Fried (1996), pp. 29-38.
} 
tienen fuente legal o extracontractual, en oposición a quienes han podido decidir sobre su posición de acreedor ${ }^{93}$. Una entidad financiera acreedora del deudor en virtud de la concesión de crédito a través de una tarjeta de crédito no sólo puede conocer previamente al nacimiento de la obligación, el estado patrimonial del (futuro) deudor, sino también monitorear su comportamiento y tomar medidas para mitigar los riesgos asociados a la concesión de crédito (entre ellos, el riesgo de sobreendeudamiento). La situación es distinta en el caso de un acreedor involuntario: un infante acreedor de alimentos o la víctima de lesiones graves cometidas dolosamente, carecen de la posibilidad de decidir vincularse jurídicamente con el deudor y de la oportunidad para tomar medidas a fin de mitigar el riesgo de sobreendeudamiento del consumidor ${ }^{94}$. La falta de un tratamiento diferenciado de los acreedores voluntarios e involuntarios es una "laguna oculta" de la regla de discharge que debe ser corregida por la vía interpretativa ${ }^{95}$ : no es razonable trasladar el riesgo de sobreendeudamiento a los acreedores involuntarios.

Lo anterior justifica una reducción teleológica del ámbito de aplicación de la regla de discharge exclusivamente a las obligaciones crediticias de origen voluntario (excluyendo, por ejemplo, las deudas de alimentos o por multas) ${ }^{96}$. En otras palabras, los acreedores involuntarios deben quedar excluidos del ámbito de aplicación de la regla de exoneración legal de los saldos insolutos una vez firme la resolución de término. Siguiendo ese canon interpretativo, por ejemplo, la referencia al "origen legal y naturaleza jurídica" de las obligaciones listadas en el Oficio Circular No 1 de la SIR adquiere consistencia: (casi) todas

\footnotetext{
${ }^{93}$ GARRIDO (2004), p. 1651. En sentido similar, se ha sostenido que el crédito involuntario es "una categoría en la que la generación del crédito no reconoce en absoluto ninguna causa vinculada a la voluntad del acreedor, sino que, el crédito se produce con prescindencia y aún en contra de esa voluntad" (DASSO (2009), p. 2).

${ }^{94}$ Aunque ya hemos sostenido que los legisladores de la NLC no han sido particularmente afortunados al redactar la regla en estudio y, por consiguiente, es dudoso encontrar el espíritu de la norma en la literalidad de sus palabras, es un hecho que el texto normativo en estudio utiliza la expresión "deudas contraídas" y no la frase "obligaciones del fallido", como hacía la legislación previa. En nuestra opinión la expresión "deudas contraídas" debe interpretarse en consonancia con la interpretación sistemática defendida en el cuerpo de este trabajo y no contradictoriamente. En efecto, la referida expresión puede interpretarse como referida a cualquier obligación (en concordancia con el art. 2284 Cc., según me lo hizo notar el profesor Juan Luis Goldenberg al comentar una versión previa de este trabajo y a quien agradezco sus observaciones). Con todo, también es posible interpretar esa expresión en el sentido de "asumir una obligación", según propone la RAE. Y este último sentido de aceptación de una responsabilidad concuerda plenamente con la interpretación sistemática de afectar el discharge solamente a los créditos voluntarios, debiendo, en nuestra opinión, por esa razón, prevalecer.

${ }^{95}$ LARENZ (2001), p. 385.

${ }^{96}$ LAReNZ (2001), pp. 385-391.
} 
las obligaciones listadas corresponden a acreedores forzosos, aunque el listado es incompleto.

\subsubsection{La buena fe como límite del efecto extintivo}

A falta de una norma concursal legal expresa que limite la concesión del beneficio de la exoneración legal de los saldos insolutos, cabe preguntarse si es posible considerar a la buena fe del deudor como un requisito de procedencia del discharge. La doctrina y la jurisprudencia han destacado el hecho de ser la buena fe un principio, no sólo de los contratos, sino de todas las obligaciones, tanto en la fase de cumplimiento o incumplimiento de una obligación como en el ejercicio de un derecho ${ }^{97}$.

La exoneración legal de los saldos insolutos tras el término de un concurso es un derecho del consumidor, inserto en la fase de cumplimiento de una obligación, que debe ser ejercido de buena fe. Si un acreedor demuestra la mala fe del consumidor (sea al momento de contratar, sea al inicio o secuela del procedimiento concursal), el tribunal debe denegar ese beneficio. Aunque el texto legal prescriba que éste operará por el solo ministerio de la ley, ello no impide entender que esa consecuencia jurídica viene atada a un supuesto de hecho, uno de cuyos elementos -si bien no expreso, sí implícito- es la buena fe en cuanto principio general del derecho al cual toda persona debe adecuar su conducta ${ }^{98}$.

La forma como la buena fe debe limitar el ejercicio del derecho del consumidor a obtener el discharge, queda bien ilustrada por la jurisprudencia de otros países. Originalmente, la Insolvenzordnung no impedía que un deudor expulsado de un procedimiento concursal por incumplir los deberes de colaboración, pudiera iniciar nuevamente un procedimiento concursal, a fin de obtener la exoneración legal de los saldos insolutos. La jurisprudencia alemana entendió

\footnotetext{
${ }^{97}$ La Corte Suprema ha sostenido que la buena fe "inspira todo nuestro ordenamiento jurídico y que acorde con ello, constituye uno de los principios rectores", agregando que "manifestaciones concretas de la buena fe se advierte en todo el proceso iter contractual. En efecto tanto en la etapa de los tratos preliminares, en el instante de la celebración, en el cumplimiento y en las relaciones pos contractual" (Corte Suprema, rol № 2236-2009, 19 de octubre de 2010, cdos. $13^{\circ}$ y $16^{\circ}$ ). En nuestra doctrina, CORRAL (2010), p. 68; De la Maza (2014), p. 201; Fuero (2004), p. 501; López Santa María (2005), pp. 398 y 408-411; PeñalliLlo (2003), p. 51.

${ }^{98}$ La falta de claridad acerca de la oportunidad procesal para discutir sobre la buena fe del deudor no es un obstáculo insuperable. La Corte Suprema (rol № 1563-2017, 22 de mayo de 2017) rechazó un recurso de casación en la forma en contra de una resolución que ordenó la tramitación incidental de la petición de exclusión de un crédito (CAE) del procedimiento concursal de una persona deudora, no obstante, la NLC no prevé ese incidente especial (ni tampoco la Ley 20.027, sobre financiamiento de estudios de educación superior).
} 
que esa conducta infringía la buena fe y exigió el transcurso de un plazo de 3 años contados desde la resolución que expulsaba al deudor de un procedimiento concursal para aceptar una (nueva) solicitud de inicio de un procedimiento concursal, plazo acogido por los legisladores en una reforma posterior ${ }^{99}$. A su turno, la jurisprudencia francesa ha establecido que un deudor expulsado de un procedimiento concursal por mala fe, puede solicitar el inicio de un nuevo procedimiento concursal si alega hechos nuevos relevantes ${ }^{100}$.

La prueba de la mala fe corresponde a cualquiera de los acreedores. Con todo, en nuestra opinión, la acreditación de ciertos hechos debiera servir de prueba suficiente de la mala fe del consumidor, entre ellos, por ejemplo, si se acoge una acción revocatoria o si un deudor oculta bienes o, en fin, respecto de una "tercera oportunidad" si, dentro de los cinco años contados desde la dictación de una resolución de término, el deudor presenta una nueva solicitud de inicio de un procedimiento concursal de liquidación.

\section{Bibliografía CITADA}

Banco Central de Chile [BCCH] (2010): "Endeudamiento de los hogares en Chile: Análisis e implicancias para la estabilidad financiera". Disponible en: http:// www.bcentral.cl/financiera-de-hogares (visitado el 8 de mayo de 2017).

(2014): "Encuesta Financiera Hogares 2014". Disponible en: http://www. bcentral.cl/documents/20143/0/Presentacion_EFH_2014.pdf/6031dda5ae52-42db-d6dd-5fa13e4ea154 (visitado el 10 de abril de 2018).

(2015): "Informe de Endeudamiento de los clientes bancarios". Disponible en: https://www.sbif.cl/sbifweb3/internet/archivos/ publicacion_10992.pdf (visitado el 10 de abril de 2018).

(2016): "Informe de Estabilidad Financiera (IEF), primer semestre de 2016". Disponible en: http://www.bcentral.cl/documents/20143/ 32019/ bcch_archivo_164647_es.pdf/5b38c46f-7c6f-2db8-f372-dc250339048e (visitado el 10 de abril de 2018).

Bastante Granell, Víctor (2016): El "deudor de buena fe" en la ley de segunda oportunidad (Granada, Comares).

Beck, Thorsten; Demirgüç-Kunt, Asli; Levine, Ross (2007): “Finance, Inequality and the Poor". Disponible en: http://siteresources.worldbank.org/DEC/Resources/ Finance_Inequality_and_the_Poor.pdf (visitado el 8.05.2017).

\footnotetext{
${ }^{99}$ Bastante (2016), p. 236, con citas jurisprudenciales.

100 BASTANTE (2016), pp. 238-239, con citas doctrinales y jurisprudenciales.
} 
Bravo Kendrick, Aníbal (1929): Ley No 4558 sobre quiebras conforme a la edición oficial, comentada y concordada (Santiago, Imprenta Universitaria).

Bravo Rodríguez, Armando (1940): El sobreseimiento en las quiebras (Santiago, Benaprés y Fernández Ltda).

Bebchuk, Lucian A., Fried, Jesse M. (1996): "The Uneasy Case for the Priority of Secured Claims in Bankruptcy", en: Yale Law Journal (Vol. 105), pp. 857-934.

Borle, Peter (1992): “Non-Debtor Liability In Chapter 11: Validity of Third-Party Discharge In Bankruptcy", en: Fordham Law Review, (Vol. 61-2), pp. 421450. Disponible en: http://ir.lawnet.fordham.edu/flr/vol61/iss2/5 (visitado el 28 de abril de 2018).

BRUBAKER, Ralph (1997): "Bankruptcy Injunctions and Complex Litigation: A Critical Reappraisal of Non-Debtor Releases in Chapter 11 Reorganizations", en: University of Illinois Law Review, (Issue 4), pp. 959-1080.

Cámara de Comercio de Santiago [CCS] (2016): "Tendencias del Retail en Chile 2016". Disponible en: https://www.ccs.cl/prensa/2016/01/tendencias_retail_2016_WEB.PDF (visitado el 10 de abril de 2018).

CHOI, Laura (2009): "Financial Stress and Its Physical Effects On Individuals and Communities", en: Community Development Investment Review, Volume 5, Issue 3, pp. 120-122. Disponible en: http://www.frbsf.org/community-development/publications/ community-development-investment-review/2009/ december/financial-stress-physical-effec ts-individuals-communities/ (visitado el 18.05.2017).

Claessens, Stijn; Dell'ariccia, Giovanni; Igan, Deniz y Laeven, Luc (2010): “Crosscountry experiences and policy implications from the global financial crisis", en: Economic Policy (Vol. 25, № 62), pp. 267-293.Comisión de las Naciones Unidas para el Derecho Mercantil Internacional [Cnudmi] (2006): "Guía Legislativa sobre el Régimen de la Insolvencia". Disponible en: http:// www.uncitral.org/pdf/spanish/texts/insolven/05-80725_Ebook.pdf (visitado el 19.05.2017).

Contador, Nelson y Palacios, Cristián (2015): Procedimientos concursales (Santiago, Thomson Reuters).

Corbo, Vittorio, Schmidt-Hebbel, Klaus (2003): "Efectos Macroeconómicos de la Reforma de Pensiones, en Chile", en: AA.VV., Resultados y Desafíos de la Reforma al Sistema de Pensiones. Disponible en: https://fiapinternacional. org/wp-content/uploads/2016/01/asocfile120060904092051.pdf (visitado el 8.05.2017).

CoRRal Talcianı, Hernán (2010): Contratos y Daños por incumplimiento (Santiago, Abeledo Perrot-Legal Publishing). 
D'ALESSIO, Giovanni y IEZzI, Stefano (2013): “Household Over-Indebtedness: Definition and Measurement with Italian Data", en: Bank of Italy Occasional Paper $N^{\circ}$ 149. Disponible en: SSRN: https://ssrn.com/Abstract=2243578 (visitado el 8.05.2017).

DAsso, Ángel (2009): "El acreedor involuntario: el último desafío al Derecho concursal". Conferencia en el "VII Congreso Argentino de Derecho Concursal y V Congreso Iberoamericano sobre la Insolvencia", Mendoza. Disponible en: (visitado el 8.05.2017).

Del Fierro, Alfonso (2013): "El Derecho de Insolvencia de los Consumidores: una reforma pendiente en el sistema concursal chileno", en: Boletín Jurídico 3, Superintendencia de Quiebras. Disponible en: http://www.superir.gob.cl/ wp-content/uploads/2014/09/boletin-juridico-publicacion-n3-1.pdf (visitado el 8.05.2017).

De La MAZA, Íñigo (2014): "La buena fe como dispositivo de ponderación", en: De la Maza, Íñigo; Morales, Antonio Manuel; Vidal, Álvaro, Estudios de Derecho de Contratos (Santiago, Legal Publishing-Thomson Reuters), pp. 201-228.

Department For Business, InNovation \& SkILls [BIS] (2011): "Credit, debt and financial difficulty in Britain, 2009/10. A report using data from the YouGov DebtTrack survey". Disponible en: https://www.gov.uk/government/publications/credit-debt-and-financial-difficulty-2009-10 (visitado el 8.05.2017).

Equifax-USS (2017): "XV Informe de Deuda Morosa a Diciembre 2016". Disponible en: http://www.uss.cl/economia-y-negocios/wp-content/uploads/ sites/12/2017/01/XV-Informe-de-Deuda-Morosa-a-Diciembre-2016-USSEquifax.pdf (visitado el 11 de mayo de 2017).

European Comission (2008): "Towards a Common Operational European Definition of Over-Indebtedness". Disponible en: http://ec.europa.eu/social/ BlobServlet?docld=5093 \&langld=en (visitado el 9.05.2017).

Feibelman, Adam (2005): "Defining the Social Insurance Function of Consumer Bankruptcy", en: American Bankruptcy Institute Law Review (Vol. 13), pp. 129-186.

Fondeville, Nicole; ÖZdemir, Erhan y Ward, Terry (2010): "Research note 4/2010. Over-indebtedness". Disponible en: https://ec.europa.eu/social/ BlobServlet?docld=6708 \&langld=en (visitado el 9.05.2017).

Fondo MONetario InternaCIONAL [FMI] (2012A): "Global Stability Report: Is growth at risk?". Disponible en: https://www.imf.org/en/Publications/GFSR/Issues/ 2017 de septiembre de 27/global-financial-stability-report-october-2017/ (visitado el 10 de abril de 2018). 
Fondo Monetario Internacional [FMI] (2012B): "World Economic Outlook". Disponible en: http://www.imf.org/external/pubs/ft/weo/2012/01/ (visitado el 19.05.2017).

Fuenzalida C., Marcelo; Ruiz-Tagle, Jaime (2009): "Riesgo financiero de los hogares", en: Economía chilena, Vol. 12 № 2, pp. 35-53. Disponible en: https://www.econbiz.de/Record/riesgo-financiero-de-los-hogares-fuenzalidamarcelo/1000 9907449 (visitado el 11 de mayo de 2017).

FueYo, Fernando (2004): Cumplimiento e incumplimiento de las obligaciones (Santiago, Editorial Jurídica de Chile).

Gamble, Elizabeth (2011): "Nondebtor Releases in Chapter 11 Reorganizations: A Limited Power", en: Fordham Urban Law Journal (Vol. 38, Issue 3), pp. 821-858.

GARRIDO, José María (1999): Garantías reales, privilegios y par condijo. Un ensayo de análisis funcional (Madrid, Centro de Estudios Registrales).

GarRiDO, José María (2004): "Artículo 91", en: Rojo, Ángel; Beltrán, Emilio (2004): Comentario a la ley concursal, Segunda reimpresión (Madrid, ThomsonCivitas), Tomo I, pp. 1634-1657.

Gathergood, John (2012): "Debt and Depression: causal links and social norm effects", en: The Economic Journal, Volumen 122, pp. 1094-1114. Disponible en: http://onlinelibrary.wiley.com/doi/10.1111/j.1468-0297.2012.02519.x/ pdf (visitado el 11.05.2017).

Gómez, Rafael y Eyzaguirre, Gonzalo (2011): El Derecho de quiebras (Santiago, Editorial Jurídica de Chile).

HernándeZ, Leonardo y Parro, Fernando (2005): "Sistema financiero y crecimiento económico en Chile", en: Estudios Públicos (№ 99), pp. 97-134.

Hojman, Daniel; MiRAndA, Álvaro; RuIz-TAGle, Jaime (2016): "Debt trajectories and mental health", en: Social Science \& Medicine ( $\left.N^{\circ} 167\right)$, pp. 54-62.

INSOL (2001), "Consumer Debt Report". Disponible en: https://www.insol.org/ pdf/consdebt.pdf (visitado el 25.08.2017).

JACKSON, Thomas (1986): The Logic and Limits of Bankruptcy Law (BeardBooks, Washington).

Jensen, Michael y MeCKLING, William H. (1976): "Theory of the Firm: Managerial Behavior, Agency Costs and Ownership Structure", en: Journal of Financial Economics (No 3), pp. 305-360.

JoHnSON, Kathleen (2005): "Recent Developments in the Credit Card Market and the Financial Obligations Ratio", en: Federal Reserve Bulletin, (Volumen 91, 
No 4), pp. 473-486. Disponible en: https://www.federalreserve.gov/pubs/ Bulletin/2005/autumn05_lead.pdf (visitado el 25.08.2017).

Kemelmajer, Aída (2008): "El "sobreendeudamiento" del consumidor y la respuesta del legislador francés", en: Separata de Anales de la Academia Nacional de Derecho y Ciencias Sociales de Buenos Aires. Anticipo de "Anales" (Año LIII, No 46), pp. 1-56.

Kilborn, Jason (2008): "Comparative Cause and Effect: Consumer Insolvency and the Eroding Social Safety Net", en: Columbia Journal of European Law (No 14(3)), pp. 563-596.

Larenz, Karl (2011): Metodología de la ciencia del derecho (Barcelona, Ariel).

Levine, Ross (1997): "Financial Development and Economic Growth: Views and Agenda", en: Journal of Economic Literature, (Volumen 35, $\mathrm{N}^{\circ} 2$ ), pp. 688-726.

Liu, Yan y Rosenberg, Christoph (2013): "Dealing with Private Debt Distress in the Wake of the European Financial Crisis". A Review of the Economics and Legal Toolbox, IMFWorking Paper. Disponible en: https://www.imf.org/ external/pubs/ft/wp/2013/ wp1344.pdf (visitado el 11.05.2017).

Livshits, Igor; MacgeE, James; TerTilt, Michèle (2011): "The Democratization of Credit and the Rise in Consumer Bankruptcies", en: Economic Policy Research Institute. Working Papers. Disponible en: http://ir.lib.uwo.ca/cgi/ viewcontent.cgi ?article $=1058 \&$ context=economicsepri_wp (visitado el 11.05.2017).

López SAN LuIS, Rocío (2015): "El tratamiento del sobreendeudamiento de los particulares en Francia", en: Revista de Derecho Civil (Volumen II, No 2), pp. 207-228: Disponible en: http://nreg.es/ojs/index.php/RDC (visitado el 11.05.2017).

López Santa María, Jorge (2005): Los contratos. Parte General, $4^{a}$ edición (Santiago, Abeledo Perrot-Legal Publishing).

Montero, Juan Pablo y TarZiján, Jorge (2010): "El éxito de las casas comerciales en Chile: ¿Regulación o buena gestión?", en: BCCH Documento de Trabajo $N^{\circ}$ 565. Disponible en: https://www.sbif.cl/sbifweb/servlet/DBiblioteca? indice $=6.5 \& T_{X T}$ _ CORRELATIVO=D1294\&CTR_ CORRELATIVO=XXXXXXXXXXXXXXX (visitado el 8.05.2017).

NINO, Carlos (1983): Introducción al análisis del derecho (Barcelona, Ariel).

PeñAlLILlo, Daniel (2003): Las obligaciones (Santiago, Editorial Jurídica de Chile).

Pinto Gutiérrez, Cristián (2016): "El perfil de los hogares más endeudados en Chile". Disponible en: http://negocios.udd.cl/files/2016/04/ 
El-Perfil-de-los-Hogares-m\%C3\%A1 s-Endeudados-en-Chile-Paper-Version. pdf (visitado el 11.05.2017).

PugA VIAL, Juan Esteban (2014): El procedimiento concursal de liquidación (Santiago, Editorial Jurídica de Chile).

Ramsay, lain (2017): Personal Insolvency in the $21^{\text {st }}$ Century. A Comparative Analysis of the US and Europe (Oxford, Hart Publishing).

Rodrícuez EspitiA, Juan José (2013): "Crisis, procedimientos y descargue: los cimientos del Nuevo régimen de insolvencia de persona natural no comerciante". Disponible en: https://letrujil.files.wordpress.com/2013/09/15juanjose-rodriguez.pdf (visitado el 24.08.2017).

Ruiz-Tagle, Jaime; García, Leidy, y Miranda, Álvaro (2013): "Proceso de Endeudamiento y Sobre Endeudamiento de los Hogares en Chile", en: BCCH Documento de Trabajo No 703. Disponible en: http://www.bcentral.cl/es/faces/ bcentral/publicaciones/ fichapublicacion?id=BCCH_PUBLICACl_104699_ ES\&_afrLoop=448298510030984\&_afrWindowMode=0\&_afrWindowld=xi y4f8oam_166\#!\%40\%40\%3F_afrWindowld\%3Dxiy4f8oam_166\%26_afrLo op\%3D448298510030984\%26id\%3DBCCH_PUBLICACI_104699_ES\%26_ afrWindowMode\%3D0\%26_adf.ctrl-state\%3Dxiy4f8oam_203 (visitado el 8.05.2017).

Ruz Lártiga, Gonzalo (2017), Nuevo Derecho concursal chileno, 2 Tomos (Santiago, Thomson Reuters).

SweEt, Elizabeth; NANDI, Arijit; Adam, Emma, y McDade, Thomas (2013): "The high price of debt: Household financial debt and its impact on mental and physical health", en: Social Science \& Medicine (Vol 91), pp. 94-100. Disponible en: http://www.sciencedirect.com/science/article/pii/S0277953613002839 (visitado el 9.05.2017).

Superintendencia de Insolvencia y ReEmprendimiento [SIR] (2016): "Boletín Estadístico Libro IV del Código de Comercio, Ley No 18.175". Disponible en: http://www.superir.gob.cl/wp-content/document/estadisticas/generales/ Cifras_31.12.2015. pdf (visitado el 9.05.2017).

(2017): “Boletín estadístico, Procedimientos Concursales - Ley № 20.720. Agosto 2017". Disponible en: http://www.superir.gob.cl/informacion-y-estadisticas/informacion-y-estadisticas-ley-n-20-720/ (visitado el 5.08.2017).

TABB, Charles Jordan (1991): "The Historical Evolution of the Bankruptcy Discharge", en: American Bankruptcy Law Journal (Volumen 65), pp. 325-71.

The World Bank [WB] (2014): "Report on the Treatment of the Insolvency of Natural Persons". Disponible en: https://openknowledge.worldbank.org/ handle/ 10986/17606 (visitado el 9.05.2017). 
The World Bank [WB] (2016): "Doing Business. Resolución de la insolvencia". Disponible en: http://espanol.doingbusiness.org/data/exploretopics/ resolving-insolvency (visitado el 9.05.2017). 